\title{
Estimation, analysis and mapping of electricity consumption of a regional building stock in a temperate climate in Europe
}

\author{
Antoinette Marie Reine Nishimwe*, Sigrid Reiter \\ LEMA, Liege University, Urban and Environmental Engineering Department, Allée de la Découverte 9, Quartier Polytech 1, 4000 Liège, Belgium
}

\section{A R T I C L E I N F O}

\section{Article history:}

Received 5 July 2021

Revised 20 September 2021

Accepted 30 September 2021

Available online 4 October 2021

\section{Keywords:}

Electricity consumption modelling

Energy management

Smart city

Building stock characterization

Urban region

\begin{abstract}
A B S T R A C T
This study financed by ERDF and the Wallonia Region estimates the annual electricity consumption (EC) of building stock, including the 3 building sectors namely residential, tertiary and industrial building. The estimation takes into account appliances, electrical heating, cooling, lighting, cooking and EC by $\mathrm{m}^{2}$ on a building level. The results are spatialized on different territorial scales. Using cadastral data of more than $1,700,000$ Walloon buildings and annual EC data from a sample collected in 2012 from the energy reports, the paper assesses the EC of the whole building stock and tests to what extent different types of variables (building factors and socio-demographics) explain annual EC. It then shows which individual variables have the highest explanatory power. In contrast to many other studies, the research recognizes the problem of multicollinearity between predictors in regression analysis and uses Lasso regression to address this issue. Three separate regression models were used to study the predictors of annual EC of residential, tertiary and industrial buildings. EC building factors (appliances, auxiliary and main heating, domestic hot water and cooking) explained the largest share which is $66.46 \%$ of the variability in EC for residential buildings whereas the EC usages share for tertiary buildings (lighting, heating and domestic hot water, air conditioning, cooling, etc.) is about $50.53 \%$ and $38.55 \%$ for industrial buildings. Socio-demographic variables on their own explained about $61.59 \%, 26.34 \%$ and $3.41 \%$ of the annual EC, respectively for residential, tertiary and industrial buildings. Hence, the building variables present the highest explanatory power for EC, presumably because heating and cooling EC are included in this study. The study highlights that when attempting to explain EC related to Walloon households, including heating and cooling EC, appliances usage has the strongest predictive power in residential buildings. On the other hand, the projected decrease in EC use for heating in existing residential buildings is $-8.82 \%$ and $-10 \%$ for existing tertiary buildings while the projected increase in EC use for cooling in existing tertiary buildings is $+11.94 \%$ from 2012 to 2050 on a regional scale. These trends follow the predicted regional heating degree-days (HDD) of $-11.76 \%$ and cooling degree-days (CDD) of $14.04 \%$ for the same period based on the gated recurrent unit (GRU) an implemented deep learning (DL) model. In addition, the produced EC maps on different territorial scales show that the highest EC is seen in large and main cities in general.
\end{abstract}

(c) 2021 Elsevier B.V. All rights reserved.

\section{Introduction}

The European Union (EU) has committed to reducing its greenhouse gas (GHG) emissions by 80 to $95 \%$ in 2050 with respect to 1990 base reference [1]. While excluding emissions from land use and forestry, the total GHG emissions in Belgium decreased by 21.9\% between 1990 and 2020 [2]. It detailed the emissions from the Belgium building stock as follows: residential sector $13.3 \%$, commercial sector $4.8 \%$, transport sector $22.5 \%$ and industrial sector $46.6 \%$. The largest contribution to greenhouse gas emissions arises

\footnotetext{
* Corresponding author.

E-mail address: marie-reine.nishimwe@uliege.be (A.M.R. Nishimwe).
}

from the energy sector. In 2018 this contributed 73\% to the total emissions [2]. Despite energy efficiency improvements in electrical appliances over the last 40 years, electricity consumption (EC) of domestic appliances has increased by about $2 \%$ per year over this period [3], making EC an important research area. Hence, given the need to reduce carbon emissions significantly to mitigate climate change and meet European legal targets, it is important to understand what factors explain residential EC and how to minimise or reduce it.

The aim and scope of this study are to estimate on a building level the EC, then grow the understanding of what determines EC in buildings, with the emphasis on the contribution of various classes of predictors. The task is to answer to what extent these 


\begin{tabular}{llll}
\multicolumn{2}{l}{ List of abbreviations } & & \\
appl. & Appliances & IWEPS & Institut Wallon de l'Évaluation, de la Prospective et de la \\
auxH & Auxiliary Heating & Statistique \\
CDD & Cooling degree-days & kWh & Kilowatt Hour \\
CEC & Cooling electricity consumption & LASSO & Least Absolute Shrinkage and Selection Operator \\
cook. & Cooking & LEMA & Local Environment Management and Analysis \\
cSV & Coma Separated Values & LHV & Lower Heating Value \\
DHW & Domestic Hot Water & LN & Natural Logarithm \\
DL & Deep Learning & MH & Main Heating \\
EC & Electricity Consumption & NB & Number of Buildings \\
EIE & Energy & OLS & Ordinary Least Square \\
ERDF & European Regional Development Fund & QGIS & Quantum GIS \\
EU & European Union & RD & Relative Difference \\
GHG & Greenhouse Gas & SD & Standard Deviation \\
GIS & Geographic Information System & SS & Statistical Sector \\
GWh & Gigawatt Hour & TA & Total shape Area \\
GRU & Gated Recurrent Unit & TEC & Total Electricity Consumption \\
HDD & Heating Degree Days & TNB & Total Number of Buildings \\
HEC & Heating electricity consumption & TWh & Terawatt Hour \\
ICEDD & Institut de Conseil et d'Etudes en Développement Dur- & VIF & Variance Inflation Factors \\
& able (asbl) & WALSTAT Wallonia Statistics geoportal
\end{tabular}

different types of variables explain the annual EC in residential, tertiary and industrial buildings, including different uses of electricity: electrical appliances, electricity space heating and cooling. This study analyses which individual variables have the highest explanatory power. Afterwards, the EC use for heating and cooling is predicted considering the effect of temperature changes based on the implemented deep learning model, namely gated recurrent unit (GRU), thus, heating degree-days (HDD) and cooling degree-days (CDD) from 2020 to 2050. The developed methodology is applied to a case study, the Walloon Region, located in Belgium in the north of Europe. This region is composed of 260 municipalities, amongst them 40 main cities.

A literature review on buildings EC shows that, for many factors, findings are somewhat ambiguous and depend on the inclusion of control variables and definition of EC. Many studies constructed consecutive regression models, starting with the appliance, and adding household, dwelling characteristics and socio-demographic data. However, sample size varies according to the magnitude of the research. For example, Bedir et al. [4] assessed the EC in about 320 households in the Netherlands. Some samples are limited to less than ten households. In contrast, the analysis in this paper is based on a regional sample of more than 1.7 million buildings, including a large number of building types, various appliances used, different usages and sociodemographics. Hence, the relatively large dataset of this study allows us to uniquely quantify the impact of various types of predictors within the same sample. The regression model decomposes the annual EC into 19 building predictors and 9 socio-demographic predictors.

Furthermore, the majority of studies reviewed did not report checking and controlling for multicollinearity. Multicollinearity occurs when two or more predictor variables in a multiple regression model are highly correlated. The presence of multicollinearity means that regression coefficients cannot be reliably interpreted. In our study, for each regression analysis, variance inflation factors (VIF) are inspected to see if multicollinearity exists, and if it does, Lasso regression is carried out which sets redundant predictors to zero, therefore performing variable selection and removing multicollinearity.
The main research questions that the authors are answering in this study are:

(1) Can different methodologies be combined to estimate the EC of a regional building stock? This study combines 4 different methodologies which can be used in other studies to estimate buildings EC on a regional scale.

(2) What can be the explanatory power of different types of variables explaining the annual EC in residential, tertiary and industrial buildings? A statistical analysis using OLS (ordinary least square) models is used to get influencing parameters for each building and socio-demographic variables.

(3) How can EC be spatialized to illustrate the actual EC on different urban scales? This study uses QGIS to map the estimated EC on different territorial scales namely statistical sector, municipality and province scales. This mapping method can be used everywhere else where the required data are available to fulfil this task.

(4) How can EC used for heating and cooling be predicted to different horizons? This study predicted heating EC (HEC) and cooling EC (CEC) using GRU modelling, UK Met Office equations and energy equations to predict HEC for residential and tertiary and CEC of tertiary buildings on 3 horizons, specifically 2030, 2040 and 2050.

The innovations in this study are: (i) a combination of different methodologies to estimate and model the EC of a whole regional building stock composed of more than 1.7 million buildings, (ii) characterizing each building by its estimated EC, based on the cadastral database, (iii) combining cadastral data and sociodemographic data on the statistical sector (SS) scale to create a statistical model, using Lasso regression to remove multicollinearity of variables in this model, (iv) predicting the heating EC (HEC) for residential and tertiary buildings and cooling EC (CEC) for tertiary buildings up to 2050, thanks to the use of predicted temperature and UK Met Office equations, and (v) mapping the obtained EC results on different scales to cover the whole studied region and to analyse spatial variations on different territorial levels. 


\section{Background}

\subsection{Top-down and bottom-up methodologies}

Top-down methodologies consider the situation as a whole (for example using national electricity statistics, in our study) and try to attribute EC to the studied building with regards to its characteristics and the analysis of aggregated data. On the other hand, the bottom-up models determine the load from individual devices and consumption activities, via a progressive approach to reach higher scale levels of data presentation. In their research Fabbri and Tarabusi combined top-down and bottom-up methodologies for buildings' energy behaviour analysis using national energy statistics to attribute electricity consumption to the studied building in the first step, and represent entire system loads at dwellings scale from building characteristics and analysis of its aggregated appliances data [5]. The complementarity of these two approaches improves building electricity management. While the top-down methods drive performance improvement by ranking a building against its peers, the bottom-up methods are focused on the building's specific context.

Hong et al. and Burman et al. compared top-down and bottomup approaches based on the complexity to provide a more accurate indication of energy efficiency in non-domestic buildings [6,7]. Difficulties in acquiring adequate data were identified as a key limitation to using both approaches. Kavgic et al. identified three major issues which need to be addressed to get better output from these methodologies: first, the lack of publicly available detailed data related to inputs and assumptions, second, the lack of data on the relative importance of input parameters to predict outputs, and third, the uncertainty on the relationship between sociodemographic data and the energy consumption [8]. Many recent papers have shown the important effect of appliances ownership on total building energy consumption, with a comparatively small contribution of socio-demographics, self-reported behaviours, and attitudes towards environmentally significant behaviour and climate change $[9,10]$.

\subsection{Impact of building characteristics and appliances ownership}

Building characteristics' effect on electricity consumption is well documented. The composition of the sample is one of the most important factors to be considered during the estimation process [9]. The result variability on dwelling level can be expected to vary in magnitude depending on whether space heating is included in the electricity consumption [11,12]. Homes using electricity for heating [13-16] and hot water are shown to use more electricity compared to those heating water with gas $[15,16]$. Another selfevident effect is that in a geographically diverse sample of homes, location plays a role $[17,18]$ due to differential demand for heating (if included) and cooling.

Regarding the impact of building variables, a common finding was that detached houses have been reported to have the highest electricity consumption $[10,19,20]$. In one study, the effect of building type only played a role in winter when heating loads contributed significantly to EC [17]. Regarding building age, results vary across studies, with some studies finding a non-linear relationship between building age and electricity consumption $[10,19]$, others found an effect only in subgroups of homes with electric heating but not gas heating [13], and others reporting no effect [17]. A larger floor area is generally associated with greater electricity use $[10,17,18,20]$, and a higher floor area is more likely to signify a high consumption household [16]. Regarding the impact of additional numbers of rooms, results varied, partly depending on whether floor size was used as an additional predic- tor: once controlling for floor area, Brounen et al. found a negative effect of additional numbers of rooms on electricity consumption [10]; not controlling for floor area, Huebner et al. found a positive effect [21]. Wiesmann et al. found no effect on the number of rooms [18]; Bedir et al. found a negative effect of additional bedrooms but a positive effect for additional study and hobbies rooms [4], potentially because the latter ones are associated with additional appliances.

The number of storeys, insulation of external walls, insulation of loft, and energy-saving windows had no significant effect on annual electricity consumption [13], but in that sample, only a small subset of homes used electricity for heating, which might explain why these factors played no role. To summarize, the effect of building variables highly depends on what electricity is used for, i.e. whether it includes space and water heating. General findings are that greater floor areas and detached houses use more electricity.

Appliance ownership was an explanatory variable included in several studies, with a general finding that owning more appliances and/or using them for longer is associated with greater EC $[4,18,22]$. Specific appliances associated with greater EC were the number of refrigerators, entertainment devices, electric water heater, electric clothes dryer, and spas/pools [17]. Bedir et al. reported that general use appliances and hobby appliances use were significant predictors but that food preparation (cooking) and cleaning appliances were not [4]. However, Kavousian et al. and McLoughlin et al. have linked cooking appliances to higher EC [17,23]. In addition, the presence of an air-conditioning unit was a significant predictor [15]. The number of halogens or energy-saving light bulbs however were not significant predictors [4]. Regarding the EC without space and water heating, it is expected that appliances ownership and use, and socio-demographics would have a bigger impact [10].

\subsection{Impact of socio-demographic variables}

Larger household size is generally associated with higher electricity use. Though, the effect is not necessarily shown to be linear and depends on how the variable is coded. Using household size as a continuous predictor showed that a larger household was associated with greater EC $[4,13,15]$. However, other papers report that whilst larger households use more electricity, the per-capita consumption is lower and hence coded household size as a categorical predictor $[17,18,20,22,24]$. Looking at what factors define a high electricity user, Jones and Lomas found that households with three or more occupants were more likely to be high consumers than homes with one or two occupants [16]. They also found that households with teenagers were more likely to be high consumers of electricity, as did Brounen et al. [10].

Regarding the effect of age on households, results were ambiguous: some studies found a non-linear effect (e.g. [17]), others reporting no effect [4]. Income is another much-studied variable, with several studies finding that households with higher income were more likely to be in the category of high consumers of electricity [16], or consumed more electricity respectively $[10,18,20,21]$, even though Wiesmann stated the effect was relatively small once other variables were added in the model [18]. However, Kavousian et al. found no relationship between income and EC and suggested that this might be because the income effect is mediated by appliance ownership which was a separate variable in the analysis [17]. Bedir et al. reported that income on its own is related to EC and it is not a significant predictor controlling for other variables in regression analysis [4], including appliances, lending support to Kavousian's findings. 


\subsection{Multicollinearity between variables}

When using linear models, it is important to check multicollinearity between considered variables hence VIF is used. Some papers and books of statistics argue that a VIF greater than 10 is problematic and unacceptable since it shows serious issues of collinearity between variables within the model [25,26]. Other more conservative researchers set the limit value of VIF at 5 [27].

\subsection{Impact of climate change and inhabitant climate concern}

Santamouris et al. analysed fifteen studies examining the impact of ambient temperature on the total EC and showed that the actual increase of the electricity demand per degree of temperature increase varies between $0.5 \%$ and $8.5 \%$ [28]. This increase is the obvious response to global climate change and therefore their impacts on building heating and cooling [29]. Besides, variables such as climate change concern, house occupant self-reported energy-saving actions, etc. can lead to significant reductions of EC [30]. Huebner et al. evidenced that self-reported habit strength was significantly related to self-reported energy-consuming behaviours and to actual energy consumption (combining gas and electricity) when controlling for several building factors [31].

Darby described electricity reductions between 5\% and 15\% for users interested in environmental concern and pro-environmental behaviour [32], whereas a Swedish study found no effect [33]. One study found that households that have expressed a motivation to buy energy-efficient appliances and air conditioners have higher levels of daily minimum consumption, contrary to what might be expected [17]. The same authors found that occupants who reported turning off lights when not in use had higher electricity consumption, contrary to what might be expected. Vringer et al. found no evidence of a relationship between domestic energy requirements and values including problem perceptions of climate change [34]. Similarly, Brandon and Lewis found that environmental attitudes did not predict historic energy consumption but were related to energy savings [35].

\subsection{Electricity consumption spatialization}

Nishimwe and Reiter modelled building heat consumption and heat demand of the whole Walloon building stock (in Belgium), at various territorial scales, but they didn't model their electricity consumption [36]. In other countries, Cao et al. analysed the spatial and temporal change in EC between 1994 and 2009, Shi et al. estimated and compared the spatiotemporal urban EC changes, and Bourgeois et al. used regression models considering socioeconomic and demographic variables and mapped energy behaviour with a sample of 1950 houses in Paris to see spatial and temporal changes [37-39]. Few studies have spatialized the EC of the regional building stock.

\section{Research methodologies}

For each building of the studied building stock, the average unitary electric consumptions are calculated using a yearly national survey report $[40,41]$. The estimated annual EC break down was done in residential buildings according to appliances type (e.g., $\mathrm{TV}$, lighting, fridges, cookers, etc.) and in tertiary buildings according to usages (lighting, air conditioning, etc.) and activity type (e.g., employees, number of students in schools, number of beds in health care and hospitals, etc.). Both cadastral and sociodemographic data were combined with the appliances and usages consumption to the next step of the bottom-up process which consists in estimating for each statistical sector scale, the amount of electricity used for each group of building type. The estimation of the annual EC of each industrial building is based on the constructed space in $\mathrm{m}^{2}$ calculated in the cadastral database. The developed model was used to build a GIS database of EC for the entire regional building stock. The OLS models showed which variable has the highest explanatory power in each building sector.

Finally, our paper looks at the prediction of annual EC use for space heating in residential and tertiary buildings and cooling in tertiary buildings due to change in temperature. The authors have performed GRU models to forecast the temperature data from 2019 to 2050 in the previous research paper [42]. The HDD and CDD were calculated using the UK Met Office equations applied to the forecasted monthly temperatures with the base temperature of $15{ }^{\circ} \mathrm{C}$ for EC use for heating in residential and tertiary buildings, and $22{ }^{\circ} \mathrm{C}$ for EC use for cooling for tertiary buildings. Then, the EC for cooling was predicted. In a final step, the results were compared to the national consumption statistics and their deviation in percentage was represented.

In the next section, the case study is described (see Fig. 1). This research concerns the south part of Belgium in Europe, the Walloon Region, which includes more than 1,700,000 buildings. The next sections will present used data and explain research methodologies in detail. The used methodologies are graphically represented in Fig. 2. They consist of four main tasks namely the topdown, bottom-up, statistical analysis and mapping processes.

\subsection{Case study}

Wallonia is located in Belgium, in the northern part of Europe. This region is composed of 5 provinces, 20 urban regions (boroughs), 262 municipalities (with 40 main cities) and 9876 statistical sectors (SS) [43], shown in Fig. 1. The SS corresponds to a neighbourhood in urban areas or a village in rural areas with more than 150 inhabitants [44]. The 40 main municipalities are mostly big cities, very densely populated compared to the other municipalities.

\subsection{Data description}

The used databases in this study are summarized in Table 1. They are the cadastral database, composed of building categories, shape areas, floor numbers, attics etc., regional energy reports for the EC by usages and appliances, shapefiles used for GIS (geographic information system), and socio-demographic data mainly used in statistical analysis. Socio-economic data could be of great interest but this study lacks that kind of data and did not use them.

The considered cadastral database in this study is composed of $1,509,697$ residential dwellings, 157,205 tertiary buildings and 39,736 industrial buildings.

\subsection{Top-down and bottom-up data processing}

The cadastral database together with the ICCED annual report on energy consumption breaks down variables in a top-down process to enable estimate the electricity consumption according to building sector (residential, tertiary and industrial) and appliance type (e.g., lighting, fridge, cooker, washing machine, TV, etc.) This is the first step in data mining. On one hand, the cleaning process applied to the huge cadastral database allowed to keep buildings of interest. For example, agriculture facilities, train and bus stations, were removed from the data because they are out of the scope of this study. Also, unclosed and unidentified buildings defined as such in the GIS shape files were not considered. On the other hand, the annualized energy consumption was estimated on basis of ICCED reports. The task consists of estimating for each residential and tertiary building type the amount of electricity used for each 


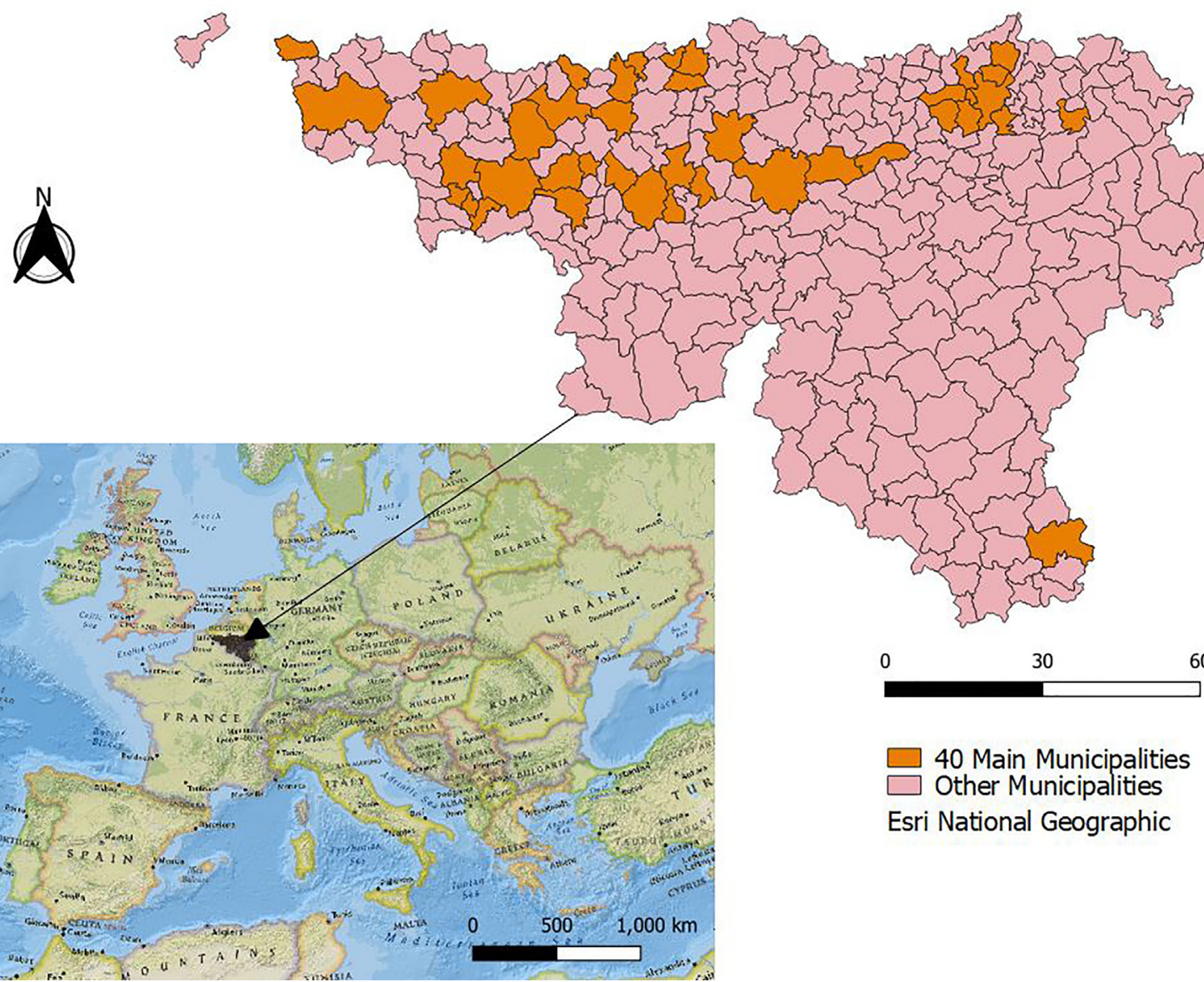

Fig. 1. Case study: 262 municipalities with 40 main municipalities in Wallonia Region, Belgium (Source: Nishimwe \& Reiter [36]).

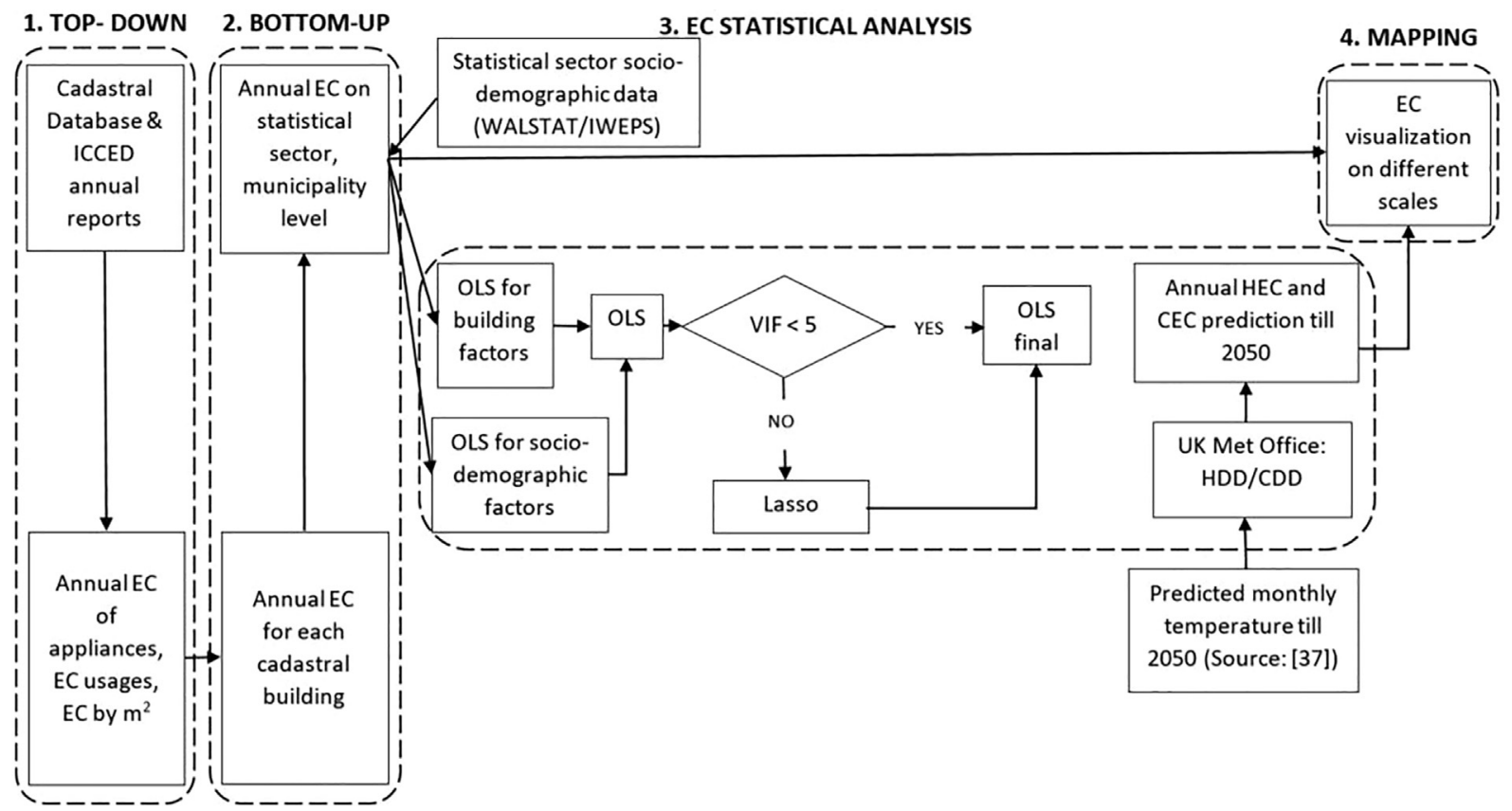

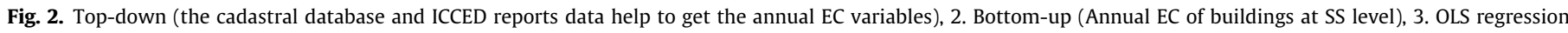

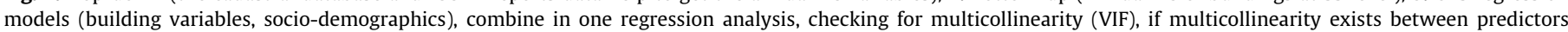
perform Lasso regression, produce the final OLS; HEC and CEC prediction analysis. 4. Mapping the electricity consumption on SS and regional scale. 
Table 1

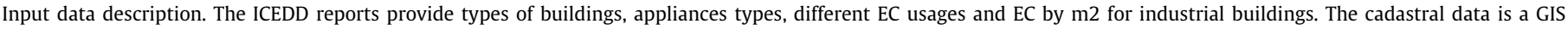
database composed of residential, tertiary and industrial buildings.

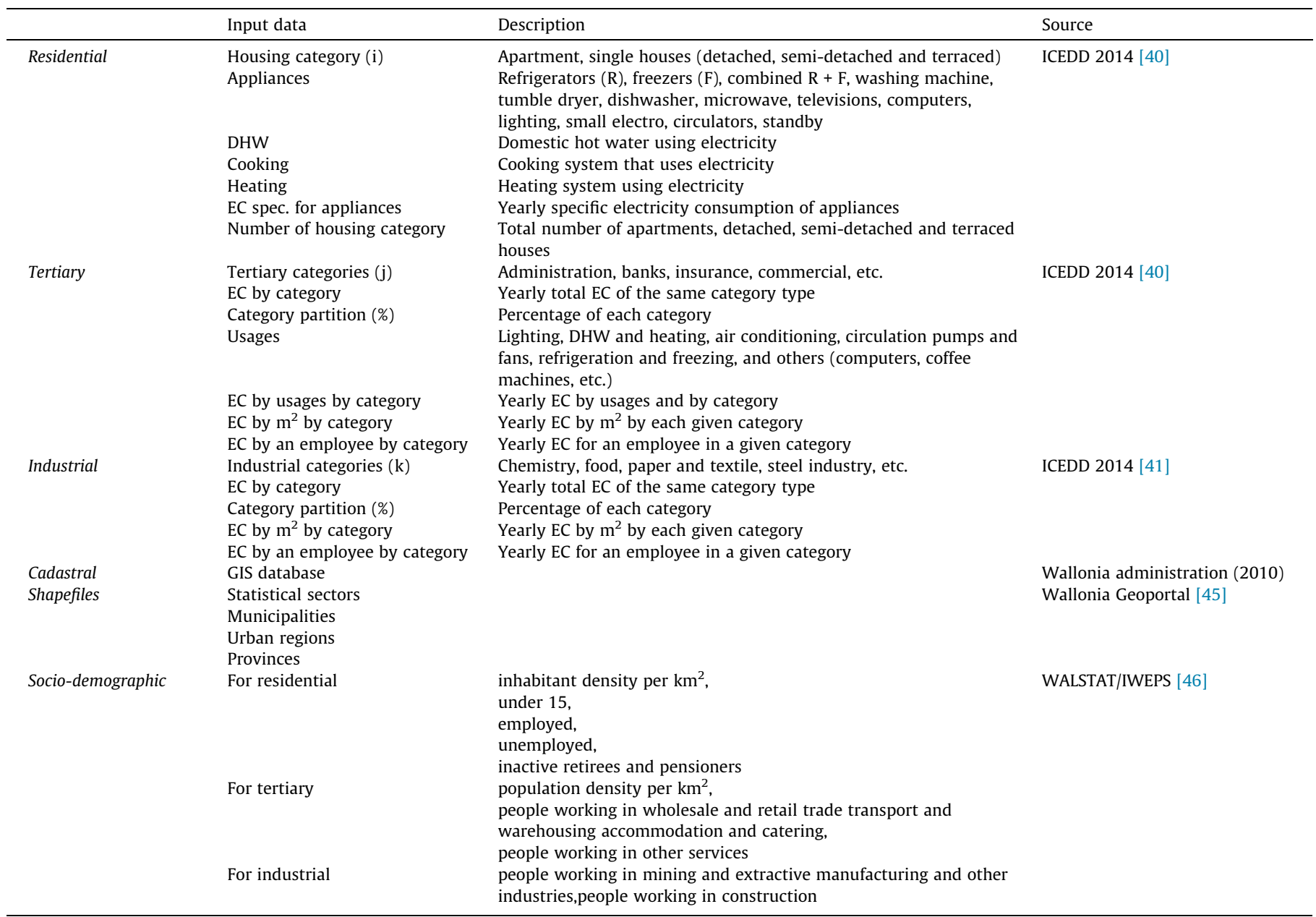

group of electric appliances, and for industrial buildings types their electricity use per square meter (Table.1). For example, the estimation of the EC of schools (including universities) and hospitals is based respectively on the number of students and of beds per building. Many appliances and human activities impact the EC consumption; however, it is hard to find the data for some factors and others are too small to be used in analysis or hard to interpret, thus they were excluded from this study.

In the bottom-up approach, the annual EC was grouped according to building sectors for each SS. The corresponding sociodemographic data were attached to the newly created database before the statistical analysis starts. The EC estimation is performed differently depending on the data availability for each building sector.

\subsubsection{Residential sector}

The EC in the residential sector is estimated based on usages (cooking, DHW, auxiliary heating and main heating which use electricity) and appliances (see Table 1). Firstly, the appliances EC is estimated as follow:

$N B_{\text {i,appl. }}=T N B_{\text {appl. }} * p_{i}$

where NB is the number of buildings, $\mathrm{NB}_{\mathrm{i}, \text { appl. }}$ is the number of buildings of category i equipped by appliances appl.; TNB is the total number of buildings and $\mathrm{p}_{\mathrm{i}}$ is the percentage of buildings of the category $i$.
$E C_{i, a p p l .}=E C_{\text {spec.,appl. }} * N B_{i, a p p l}$

$\mathrm{EC}_{\mathrm{i}, \mathrm{appl}}$ is the consumption of appliances by category $\mathrm{i}, \mathrm{EC}_{\text {spec. }}$ appl. is the specific consumption of the given appliance.

$E C_{r, a p p l .}=\sum\left(E C_{i, a p p l .} / N B_{i}\right)$

where $\mathrm{EC}_{\mathrm{r}, \mathrm{appl}}$ is the electricity consumption of the residential housing based on the appliances it is equipped with and $\mathrm{NB}_{\mathrm{i}}$ is the number of buildings of category i. The EC of domestic hot water (DHW) $\left(E C_{r, D H W}\right)$ and of the main heating $\left(E C_{r, M H}\right)$ are given in the ICEDD report.

Secondly, the estimation of the total electricity used for auxiliary heating and for cooking is estimated by the authors following the next formula:

$E C_{r, \text { cook }}=T E C_{\text {cook }} * p_{i}$

where $\mathrm{EC}_{\mathrm{r}, \mathrm{cook}}$ is the use of electricity in cooking for one single housing, $\mathrm{TEC}_{\mathrm{cook}}$ is the total electricity used for cooking and $\mathrm{p}_{\mathrm{i}}$ is the percentage of buildings of category i.

$E C_{r, a u x H}=T E C_{a u x H} * p_{i}$

Here, $\mathrm{EC}_{\mathrm{r} \text {,auxH }}$ is the electricity used for auxiliary heating for one single housing and $\mathrm{TEC}_{\mathrm{auxH}}$ is the total electricity used for auxiliary heating. 
Lastly, the EC of a residential building in the cadastral database is:

$E C_{r}=E C_{r, a p p l .}+E C_{r, D H W}+E C_{r, M H}+E C_{r, \text { cook }}+E C_{r, a u x H}$

\subsubsection{Tertiary buildings}

The estimation of EC in the tertiary sector considers usages described in Table 1 using formula 7:

$E C_{\text {tert }}=E C_{j, u} / N B_{j}$

where $\mathrm{EC}_{\text {tert }}$ is the electricity consumption of a tertiary building in the cadastral database, $\mathrm{EC}_{\mathrm{j}, \mathrm{u}}$ is the electricity consumption of usage $\mathrm{u}$ by building category $\mathrm{j}$ and $\mathrm{NB}_{\mathrm{j}}$ is the number of tertiary buildings of category $\mathrm{j}$.

\subsubsection{Industrial buildings}

Because of the lack of usages data for the industrial sector, the authors considered using the EC by shape area as given in the ICEDD report. Hence, the EC of industrial buildings is estimated as follows:

$E C_{k}=T E C_{k} / T A_{k}$

where $\mathrm{EC}_{\mathrm{k}}$ is the electricity consumption of an industrial building category $\mathrm{k}, \mathrm{TEC}_{\mathrm{k}}$ is the total EC of industrial buildings of the same category $\mathrm{k}$ and $\mathrm{TA}_{\mathrm{k}}$ is the total shape areas of industrial buildings of the same category k. Hence, the EC of an industrial building in the cadastral database is given by:

$E C_{\text {ind }}=E C_{k} * S_{c}$

where $S_{c}$ is the shape area of an industrial building in the cadastral database.

Afterwards, the obtained data above is applied to the cadastral database. Therefore, each cadastral building is characterized by its EC. This last is used as the input for statistical analysis and cartography.

\subsection{Statistical analysis ordinary least square, VIF, Lasso regression and EC predictions}

The statistical analysis and modelling are performed using Excel and $\mathrm{R}$ software.

\subsubsection{Ordinary least square (OLS)}

The OLS regression analysis was carried out for each of the three building sectors (residential, tertiary and industrial). The analysis was done on the statistical sector level. The dependent variable used was the annual EC in gigawatt-hours (GWh) and it was log- transformed (natural $\log$ ) to achieve greater symmetry of the distribution, and of the residuals in the regression analysis. The independent variables used as predictors are presented with their frequencies or summary statistics (means and standard deviation) in Table 4.

Predictors were grouped in two different factors: building and socio-demographic. In the first step, OLS regression analysis was performed for each predictors group separately. After building all individual models (building and socio-demographic), models were then successively combined until resulting in a final model encompassing all predictors. Thus, showing which individual predictors have the highest explanatory power of the annual EC in residential, tertiary and industrial buildings, including electricity for space and water heating using separate models, and then in a combined model. The next step was checking and if necessary, controlling for multicollinearity.

\subsubsection{Variance-inflation factors (VIF)}

Given the suspected issue of multicollinearity, the varianceinflation factors (VIF) were then inspected. The glmnet package was installed in $\mathrm{R}$ software for this analysis. If VIFs greater than 10 were found in the OLS regression, then the least absolute shrinkage and selection operator (Lasso regression) was employed.

\subsubsection{Lasso regression}

In our study, for each regression analysis, predictors were inspected to see if multicollinearity exists, and if it does, Lasso regression is carried out which sets highly correlated predictors to zero, therefore performing variable selection and removing multicollinearity. Examples include the "Unemployed" correlating with "Employed". For further knowledge on how Lasso regression is applied on variables in R, the book of James $\mathrm{G}$. et al. is recommended [26]. After identifying which coefficients were set to zero using Lasso, then a new OLS was repeated omitting one of those predictors.

\subsubsection{Focus on EC use for heating and cooling/air-conditioning - analysis and prediction}

Belgium's temperate climate implies a low use of cooling systems in the residential sector. In 2016, 92\% of Belgian residential households had neither a fixed air conditioning unit nor a mobile air conditioning unit. The distribution of air conditioning and cooling in the Belgian residential sector is known neither on the building level nor on any territorial level. Only $0.3 \%$ of the electricity consumed by Belgian residential households was used for cooling in 2017 [47] which equals 0.02 TWh LHV for the Wallonia Region,

Table 2

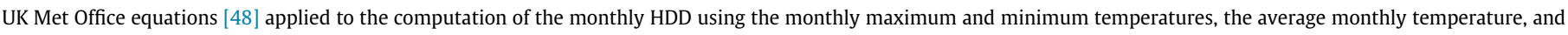
the base temperature.

\begin{tabular}{|c|c|c|c|}
\hline Case & Weather & Condition & $\mathrm{HDD}_{\text {month }}=$ \\
\hline 1 & Uniformly cold month & $T_{\max } \leq T_{\text {base }}$ & $\left(T_{\text {base }}-T_{\text {avg }}\right)(10)$ \\
\hline 2 & Mostly cold month & $T_{\text {avg }} \leq T_{\text {base }}<T_{\max }$ & {$\left[\left(T_{\text {base }}-T_{\min }\right) / 2\right]-\left[\left(T_{\max }-T_{\text {base }}\right) / 4\right](11)$} \\
\hline 3 & Mostly warm month & $T_{\min }<T_{\text {base }}<T_{\text {avg }}$ & $\left(T_{\text {base }}-T_{\min }\right) / 4(12)$ \\
\hline 4 & Uniformly warm month & $T_{\min } \geq T_{\text {base }}$ & 0 (No heating is required) \\
\hline
\end{tabular}

Table 3

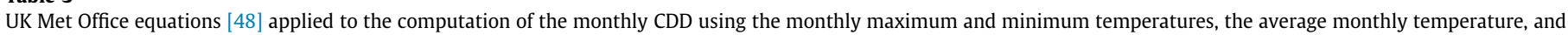
the base temperature.

\begin{tabular}{|c|c|c|c|}
\hline Case & Weather & Condition & $\mathrm{CDD}_{\text {month }}=$ \\
\hline 1 & Uniformly warm month & $T_{\min } \geq T_{\text {base }}$ & $\left(T_{a v g}-T_{\text {base }}\right)(13)$ \\
\hline 2 & Mostly warm month & $T_{\min }<T_{\text {base }}<T_{\text {avg }}$ & {$\left[\left(T_{\max }-T_{\text {base }}\right) / 2\right]-\left[\left(T_{\text {base }}-T_{\min }\right) / 4\right](14)$} \\
\hline 3 & Mostly cold month & $T_{\text {avg }}<T_{\text {base }}<T_{\max }$ & $\left(T_{\max }-T_{\text {base }}\right) / 4(15)$ \\
\hline 4 & Uniformly cold month & $T_{\max } \leq T_{\text {base }}$ & 0 (No cooling is required) \\
\hline
\end{tabular}


our case study. Therefore, this study did not consider the residential sector in cooling analysis and prediction. The industrial sector is not considered too because of the lack of required data. Regarding the EC use for heating, this study considered residential and tertiary sectors to predict the heating electricity consumption (HEC) and the cooling electricity consumption (CEC). For EC use for cooling, the only tertiary sector is considered. The analysis shows the impact of climate in EC use for heating in the residential and tertiary building sectors, and EC use for cooling in the tertiary building sector up to the 2050 horizon.

The UK Met Office equations used in this part of the research are based on a comparison between the maximum, minimum and base temperature (Tables 2 and 3). In this study, these equations were applied to the predicted monthly maximum $\left(\mathrm{T}_{\max }\right)$ and minimum temperatures $\left(\mathrm{T}_{\text {min }}\right)$. These predicted temperatures were defined in a previous study by Nishimwe and Reiter on assessing the impact of climate change on Wallonia building stock heat consumption. GRU model has been used to forecast the $\mathrm{T}_{\max }$ and $\mathrm{T}_{\min }$ from 2019 to 2050 [42]. The monthly HDD values were computed using a base temperature ( $\mathrm{T}_{\text {base }}$ ) of $15^{\circ} \mathrm{C}$ (Table 2 ), whereas the monthly CDD used a base temperature of $22{ }^{\circ} \mathrm{C}$ (Table 3 ).

First, for residential buildings, the authors considered a correction factor of 0.75 which corresponds to $75 \%$ for heating-based systems and of 0.25 corresponds to $25 \%$ domestic hot water using electricity. Second, for tertiary buildings, the factor of 0.85 which corresponds to $85 \%$ of cooling/heating-based system and a factor

Table 4

Building and socio-demographic factors - summary statistics of continuous variables.

\begin{tabular}{|c|c|c|}
\hline Predictor & Mean & $\begin{array}{l}\text { Standard } \\
\text { deviation (SD) }\end{array}$ \\
\hline \multicolumn{3}{|l|}{ Residential } \\
\hline \multicolumn{3}{|l|}{ Building variables: } \\
\hline Apartment & 7.383 & 24.62205 \\
\hline Terraced & 48.33 & 108.1906 \\
\hline Semi Detached & 45.35 & 63.76053 \\
\hline Detached & 56.92 & 63.42967 \\
\hline \multicolumn{3}{|l|}{ Socio-demographic variables: } \\
\hline Density (hab $/ \mathrm{km}^{2}$ ) & 1085 & 1508.517 \\
\hline Under_15_Years & 64.97 & 80.16327 \\
\hline Employed & 137.6 & 156.5005 \\
\hline Unemployed & 19.27 & 34.17129 \\
\hline Inactive_Retirees_Annuitants & 66.01 & 88.92442 \\
\hline \multicolumn{3}{|l|}{ Tertiary } \\
\hline \multicolumn{3}{|l|}{ Building variables: } \\
\hline Administration & 1.23 & 4.221061 \\
\hline Other \& Miscellaneous & 0.3952 & 1.202021 \\
\hline Banks_Insurance_Business & 0.8661 & 2.022129 \\
\hline Commerce & 8.181 & 24.1762 \\
\hline Culture_Sport \& Other Services & 5.486 & 18.49036 \\
\hline Education & 1.584 & 3.676335 \\
\hline Health Care \& Hospital & 0.5399 & 1.821924 \\
\hline Transport \& Communication & 0.1228 & 0.5501325 \\
\hline \multicolumn{3}{|l|}{ Socio-demographic variables: } \\
\hline Density $\left(\mathrm{hab} / \mathrm{km}^{2}\right)$ & 1085 & 1508.517 \\
\hline $\begin{array}{l}\text { People working in } \\
\text { wholesale_retail_warehousing_Restaurant }\end{array}$ & 31.99 & 37.3211 \\
\hline People working in other Services & 5.702 & 7.33062 \\
\hline \multicolumn{3}{|l|}{ Industrial } \\
\hline \multicolumn{3}{|l|}{ Building variables: } \\
\hline Food & 0.3549 & 1.573659 \\
\hline Other Industry & 5.315 & 8.300523 \\
\hline Chemistry & 0.1865 & 3.924575 \\
\hline Metal Fabrication & 0.1408 & 1.586539 \\
\hline Non-Metallic Minerals & 0.1084 & 2.359441 \\
\hline Steel Non-Ferrous & 0.01086 & 0.4626685 \\
\hline Textile \& Paper & 0.09507 & 2.257449 \\
\hline \multicolumn{3}{|l|}{ Socio-demographic variables: } \\
\hline $\begin{array}{l}\text { People working in manufacturing \& Mining } \\
\text { Extractive }\end{array}$ & 20.44 & 22.04651 \\
\hline People working in construction & 12.37 & 12.80149 \\
\hline
\end{tabular}

of $0.15(15 \%)$ of pumps and fans used for cooling. Hence, the predicted HEC and CEC is calculated using the following formulas:

$E C_{y, r, h}=\left(\left(0.75 * E C_{r e f, r, h}\right) *\left(H D D_{y} / H D D_{r e f}\right)+\left(0.25 * E C_{r e f, r, h}\right)\right.$

$E C_{y, t, h}=\left(\left(0.85 * E C_{r e f, t, h}\right) *\left(H D D_{y} / H D D_{r e f}\right)+\left(0.15 * E C_{r e f, t, h}\right)\right.$

$E C_{y, t, c}=\left(\left(0.85 * E C_{r e f, t, c}\right) *\left(C D D_{y} / C D D_{\text {ref }}\right)+\left(0.15 * E C_{\text {ref }, t, c}\right)\right.$

where $\mathrm{EC}_{\mathrm{ref}, \mathrm{r}, \mathrm{h}}$ is the reference value for residential HEC in $2012, \mathrm{EC}_{\mathrm{y}}$, $\mathrm{r}, \mathrm{h}$ is the present annual HEC values for residential buildings, $\mathrm{r}$ stands for residential buildings, $\mathrm{HDD}_{\mathrm{y}}$ is the heating degree-days of the present year and $\mathrm{HDD}_{\text {ref }}$ is the reference year (2012) heating degree-days. For tertiary buildings, the subscript $t$ is used (formula 17). $\mathrm{EC}_{\mathrm{ref}, \mathrm{t}, \mathrm{c}}$ is the reference value for tertiary $\mathrm{CEC}, \mathrm{EC}_{\mathrm{y}, \mathrm{t}, \mathrm{c}}$ is the actual annual CEC values for tertiary buildings and the $C_{D D}$ stands for the cooling degree-days of the present year while $\mathrm{CDD}_{\text {ref }}$ is the cooling degree-days of the reference year (2012).

\subsection{EC cartography}

The estimation of EC is implemented on the building level considering different usages for residential and tertiary sectors and by shape area for the industrial sector because the authors did not find detailed information on usages in the industrial sector. The estimation is performed using Excel and $\mathrm{R}$ for calculations and QGIS software for mapping. Each building is represented by its EC and the results are mapped on 3 territorial scales. The maps use graduated symbology with Natural Breaks of Jenks for classification on SS and municipality scales, as for the mapping of the Wallonia heat consumption and demand of the previous study [36]. However, on the province scale, the quantile classification with equal counts is used because in our case study, Wallonia has only 5 provinces and the authors prefer to divide feature values into equal size spans.

\subsection{Methodological framework}

All the used methodologies are summarized in Fig. 2.

\section{Results and discussion}

To characterize each building by its EC, through the top-down approach as explained earlier, the authors calculated EC of different usages for residential and tertiary sectors (Fig. 3 and Fig. 4) and the EC by $\mathrm{m}^{2}$ for the industrial sector (Fig. 5).

Fig. 3 shows that the appliances are very consuming in the residential sector compared to other usages. For apartments, the annual average EC of appliances is $2749.51 \mathrm{kWh}$ LHV, whereas for detached, semi-detached and terraced houses it is equal to $2712.79 \mathrm{kWh}$ LHV. Also, the auxiliary heating and cooking have the same values for terraced, semi-detached and detached houses and are $262.08 \mathrm{kWh}$ LHV and 468.47 kWh LHV respectively, while they are $210.11 \mathrm{kWh}$ LHV and $375.57 \mathrm{kWh}$ LHV respectively for an apartment. DHW and the main heating vary for each housing type. DWH and main heating are higher in a detached house. DWH is lower in the apartment and the main heating is lower in the terraced house.

Fig. 4 shows that, in the tertiary sector, 6 usages are detected in the ICEDD report, namely air-conditioning, cooling, heating and DHW, lighting, pumps and circulation fans and others (which are televisions, computers, microwaves and other appliances). In general, lighting and others are higher in every tertiary subsector, whereas heating and DHW are lower in many tertiary subsectors and inexistent in other services and miscellaneous. The commerce sub-sector is the most consuming in terms of lighting, other consumption and refrigeration freezing usages. 


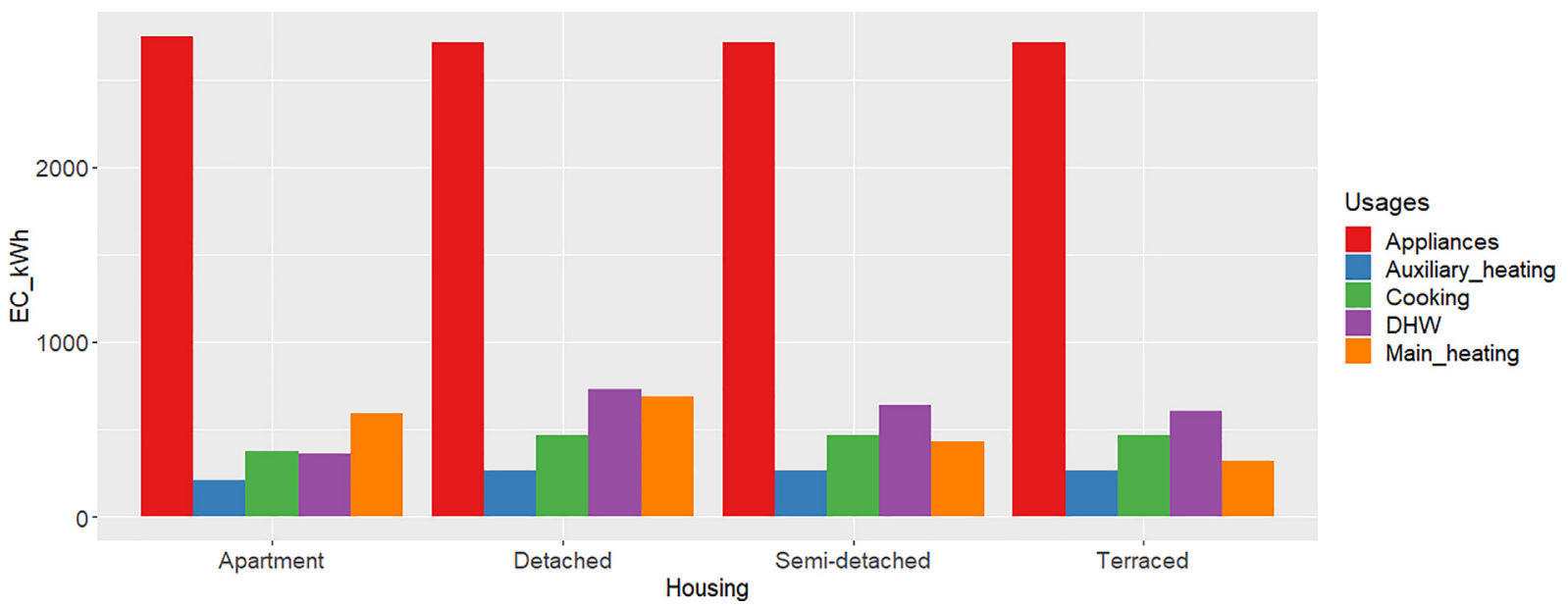

Fig. 3. Annual average EC in kWh LHV (lower heating value) of appliances and usages in residential houses.

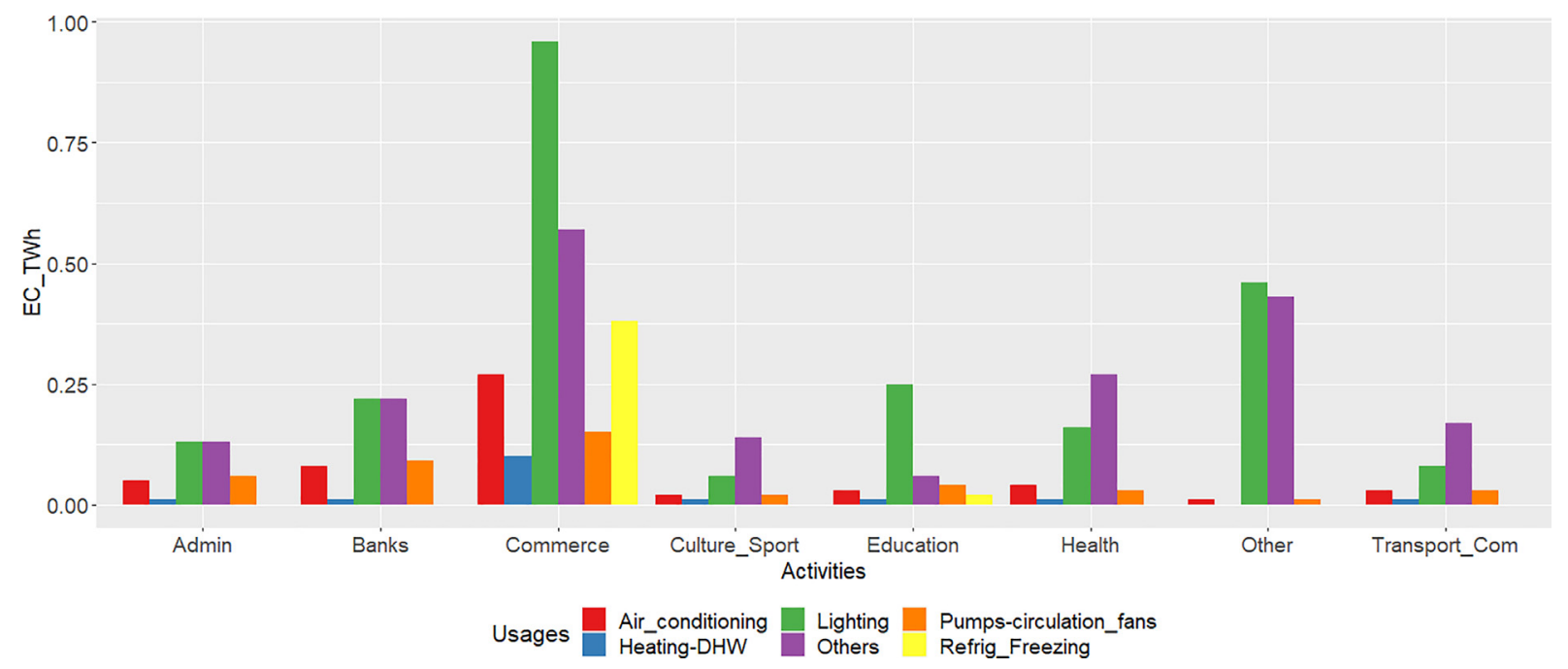

Fig. 4. Annual average EC by usage in tertiary buildings (GWh LHV).

For the industrial sector, the usages of EC are not given in the ICEDD reports. They present only the annual EC of each industrial building category. Therefore, the authors estimated the EC by $\mathrm{m}^{2}$ of each industrial building category, based on the shape areas of the cadastral database. Fig. 5 shows that Steel and nonferrous industrial buildings have the highest EC, whereas the other subsectors have lower EC.

These results from the top-down approach are integrated into the cadastral database with results of the bottom-up approach to perform the statistical analysis and map the EC on different scales.

\subsection{Statistical analysis}

\subsubsection{Descriptive statistics of predictors}

Table 3 provides descriptive statistics for the independent variables used in the OLS model. The values assigned to the variables are summed at the statistical sector level. The building variable value refers to the counted number of the variable, whereas the socio-demographic value is the number of the population associated with the variable. According to the descriptive statistics, the dominant residential building type is detached, which on average accounts for 57 houses in a SS, followed by terraced houses (48), semi-detached houses (45) and apartments (7). Trade crafts (8) together with culture, sport and other services (e.g. cinema, theatre, church) (5) are major tertiary buildings. Another industry (construction, warehouses, sawmill, etc.) (5) is the dominant industrial building on average in an SS. On the other hand, the used socio-demographic variables are mainly average density (1085 $\mathrm{hab} / \mathrm{km}^{2}$ ), employed (138), inactive and retirees (66) and habitant under 15 years (65). Although many socio-demographic factors impact the EC, few were selected for the model. Complete sociodemographic data are rare and many were discarded due to missing data.

\subsubsection{VIF and lasso regression}

Given the suspected issue of collinearity between predictors, the variance-inflation factors (VIF) were then inspected. In this study, the value of 10 was used as suggested by many studies $[25,26]$. This procedure set coefficients to zero, effectively eliminating non-relevant predictors with VIF greater than 10 out of the model. Thus, it minimizes the sum of squared errors. Four socio-demographic predictors from the residential OLS model showed VIF values above the chosen threshold criterion (Table 5). Therefore, Lasso regression was performed on the data.

All VIF for the remaining predictors were smaller than 10 except for the Under_15_Years variable (VIF = 10.33) which was kept in 


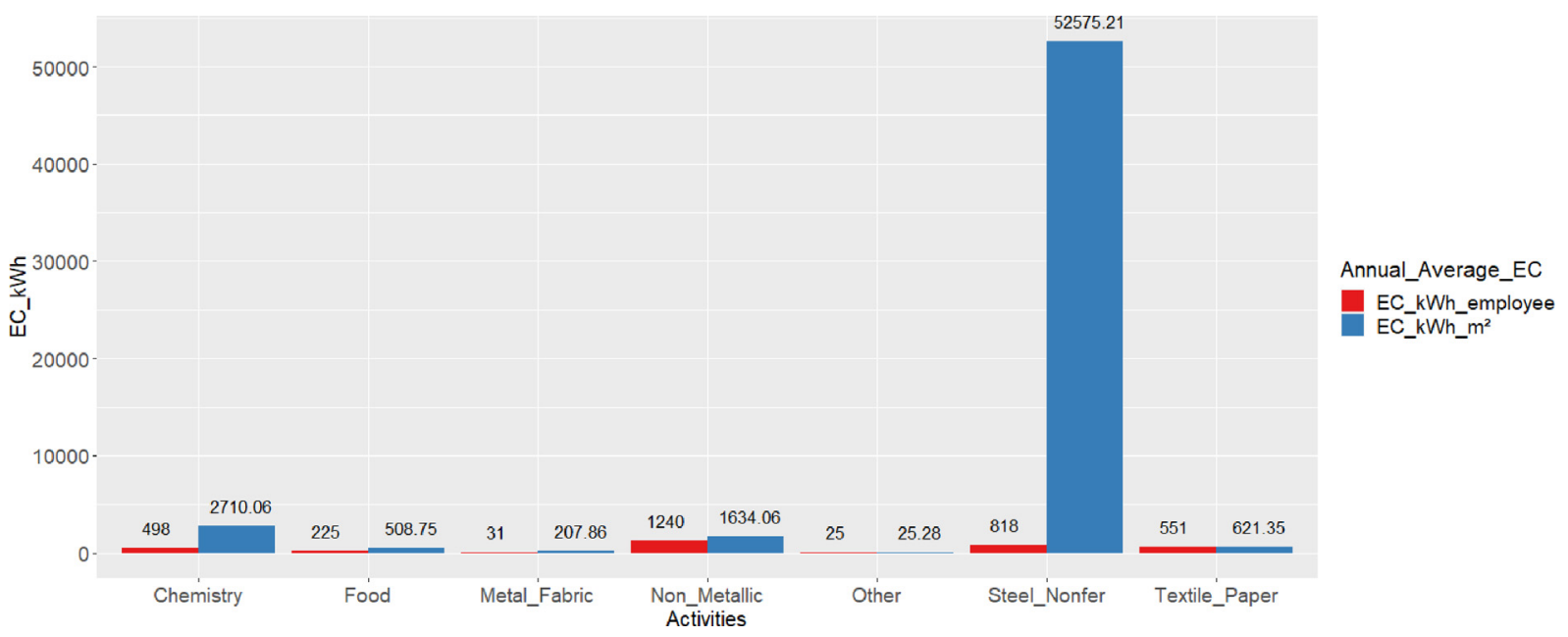

Fig. 5. Annual average EC by an employee and by $\mathrm{m}^{2}$ of industrial buildings in $\mathrm{kWh}$ LHV.

Table 5

Collinearity check for residential buildings before and after multicollinearity elimination. The Employed variable with VIF greater than 10 is excluded from the model, the variable Under_15_Years is kept for its importance in the study.

\begin{tabular}{lcc}
\hline Predictor & VIF (before) & VIF (after) \\
\hline Building variables: & & \\
Apartment & 2.383093 & 2.082155 \\
Terraced & 5.881274 & 5.450489 \\
Semi Detached & 2.622066 & 2.568346 \\
Detached & 3.135815 & 2.525560 \\
Socio-demographic variables: & & \\
Density (hab/km²) & 3.094740 & 3.093257 \\
Under_15_Years & 13.458822 & 10.331108 \\
Employed & 16.019709 & Removed \\
Unemployed & 9.062522 & 8.692325 \\
Inactive_Retirees_Annuitants & 8.130925 & 6.415412 \\
\hline
\end{tabular}

the model for its importance in the study, considering households' composition. Hence, Lasso regression was not necessary.

In Table 5, the employed parameter showed the higher collinearity with the unemployed parameter during the statistical analysis expressed by the variance-inflation factors (VIF) value of 16.019709 which is greater than the desired value of $\mathrm{VIF}<10$. Afterwards, the employed predictor was removed from the model and the VIF values recalculated to ensure the elimination of collinearity between predictors.

Fig. 6 from lasso regression shows predictor ranks from strongest to the weakest. The predictors that enter the model early are the most predictive and those that enter the model later are less important. Each coloured line represents the value taken by a different coefficient in our model. The top numbering of the plot indicates the number of predictors the model is using, going from all predictors (top left corner) to sparser models (top right corner). As log lambda $(\lambda)$ grows toward zero, fewer predictors remain in the model because more and more coefficients are zero-valued. Therefore, the apartment is the first to enter the model followed by semi-detached, detached, population density per $\mathrm{km}^{2}$, terraced, inactive population, unemployed and under 15 years' people. The remaining employed variable coefficient is set to zero and consequently removed from the final model.

In Table 6, the collinearity check is done as well for tertiary and industrial buildings and all the VIF were lower than 10, thus all variables are kept in the models.

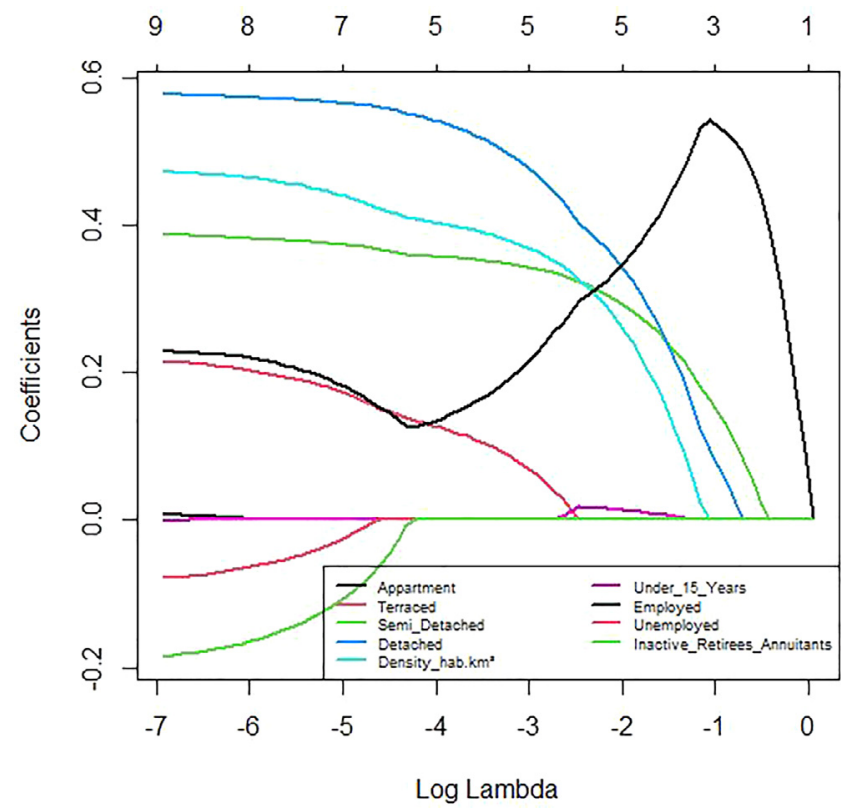

Fig. 6. Predictors coefficients scores as a function of $\log (\lambda)$ indicating the shrinkage of coefficients.

\subsubsection{Building and socio-demographic regression model}

Table 7 shows the coefficients of the OLS ( $\beta O L S$, standard error and the p-values). The stars indicate significance at the $0.001\left(^{* * *}\right)$, $\left.0.01{ }^{* *}\right)$, and $0.05\left({ }^{*}\right)$ level. The regression coefficients are in the original measurement units, e.g. for building predictors. It tells us how much EC increases when the number of the building increases by one unit (building). Only two predictors are not significant: Apartment $(p$-value $=0.762)$ and other services $(p$-value $=0.526)$. Only the predictors that had remained after the Lasso regression were included in the final OLS model.

In the first step, an individual model for each predictor group was developed. The building model explained $R^{2}=66.46 \%$ of the variability in annual electricity consumption of residential buildings, for tertiary buildings $\mathrm{R}^{2}=50.53 \%$ and $\mathrm{R}^{2}=38.55 \%$ for industrial buildings. Moreover, the socio-demographic model explained $\mathrm{R}^{2}=61.59 \%$ for residential buildings, $\mathrm{R}^{2}=26.34 \%$ for tertiary buildings and $R^{2}=3.41 \%$ for industrial buildings. In the sec- 

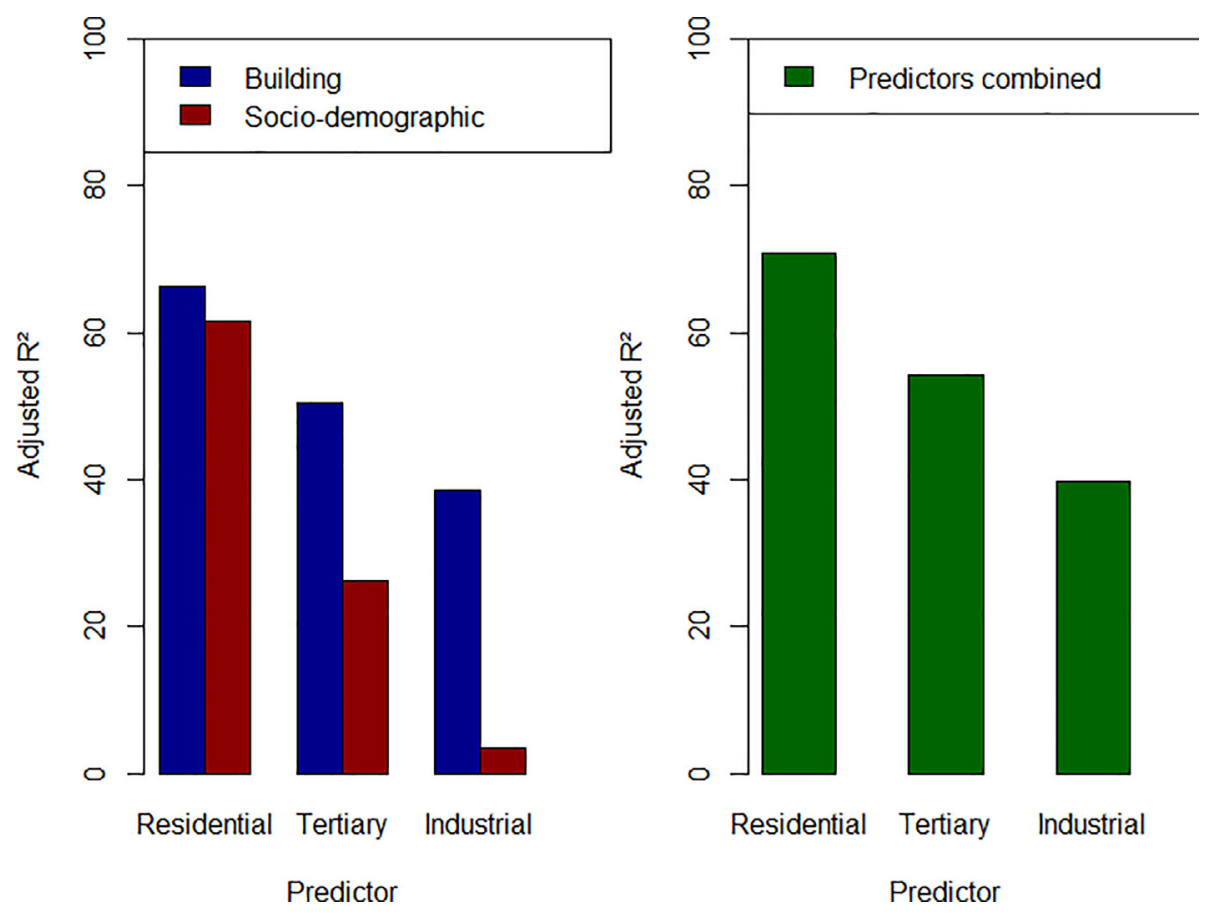

Fig. 7. Adjusted $\mathrm{R}^{2}$ for the six individual models (left) and the combined models (right).

ond step, the building and socio-demographic predictors were combined. This final model explained $\mathrm{R}^{2}=70.86 \%$ of the EC variability for residential buildings, $\mathrm{R}^{2}=54.33 \%$ for tertiary buildings and $\mathrm{R}^{2}=39.75 \%$ for industrial buildings.

4.1.4. Focus on EC used for heating in residential and tertiary buildings and EC used for cooling/air conditioning in tertiary buildings - analysis and prediction

The EC used to heat residential and tertiary buildings as well as the EC used for cooling tertiary buildings are estimated on building level and spatialised on municipality scale. The results obtained are

Table 6

Collinearity check for tertiary and industrial buildings.

\begin{tabular}{ll}
\hline Predictor & VIF \\
\hline Tertiary & \\
Building variables: & \\
Administration & 1.182668 \\
Other \& Miscellaneous & 1.025821 \\
Banks_Insurance_Business & 1.229533 \\
Commerce & 1.815894 \\
Culture_Sport \& Other Services & 1.005315 \\
Education & 1.529952 \\
Health Care \& Hospital & 1.130783 \\
Transport \& Communication & 1.041209 \\
Socio-demographic variables: & \\
Density (hab/km ${ }^{2}$ ) & 2.109514 \\
People working in wholesale_retail_warehousing_Restaurant & 5.252508 \\
People working in other Services & 4.338770 \\
Industrial & \\
Building variables: & \\
Food & 1.057827 \\
Other Industry & 1.127859 \\
Chemistry & 1.016631 \\
Metal Fabrication & 1.114709 \\
Non-Metallic Minerals & 1.009806 \\
Steel Non-Ferrous & 1.096561 \\
Textile \& Paper & 1.001432 \\
Socio-demographic variables: & \\
People working in manufacturing \& Mining Extractive & 3.780581 \\
People working in construction & 3.766945 \\
\hline
\end{tabular}

based on the GRU model. The total heating (Table 8) and cooling (Table 9) EC change rate between 2012 and future horizon (2030, 2040, and 2050) on a regional scale (whole Wallonia Region), show that the heating EC will decrease from $-6.34 \%$ to $-8.82 \%$ for residential buildings and from $-7.19 \%$ to $-10 \%$ for tertiary buildings whereas the cooling EC will increase from $8.28 \%$ to $11.94 \%$ for tertiary buildings on a regional scale.

Fig. 8 shows the projected decrease in EC used to heat residential and tertiary buildings, the increase in EC for cooling in tertiary buildings from 2012 to 2050 . This decrease or increase follows the trend of the predicted HDD of $-11.76 \%$ and CDD of $14.04 \%$ at the same period interval.

The spatialization of EC used in heating for residential (Fig. 9) and tertiary (Fig. 10) buildings sector illustrate on the left, heating EC in 2012 and on the right the heating EC in 2050. The cooling EC of the tertiary building sector in 2012 on the left and 2050 on the right are presented in Fig. 11. These three figures are on a municipality scale.

The municipalities that have higher heating EC in residential and tertiary buildings are mostly amongst main cities, whether in 2012 or horizon 2050. This is because of the existence of many residential using electricity for heating compared to other rural municipalities or villages. Regarding the electricity used for cooling or conditioning the tertiary buildings, the higher consumption is localized also in main municipalities, which require a lot of air conditioning or cooling especially in commercial buildings, such as supermarkets and hypermarkets, banks and administration offices (see Fig. 12).

\subsubsection{Summary of statistical analysis and relation to other research studies}

The OLS models showed that the building's EC is to a large extent impacted by the building usages, more specifically appliance-related variables. Other studies show that when electricity-based heating is included, building variables play a much larger role [13-16]. Considering residential buildings, the building usages explained $66.46 \%$ of EC, whereas tertiary building usages explained $50.53 \%$ of EC. However, EC in the industrial build- 
Table 7

OLS coefficients for the final combined (building and socio-demographic) regression model.

\begin{tabular}{|c|c|c|c|}
\hline Predictor & $\beta_{\mathrm{OLS}}$ & Std. Error & p-value \\
\hline \multicolumn{4}{|l|}{ Residential } \\
\hline \multicolumn{4}{|l|}{ Building variables: } \\
\hline Apartment & $1.748 \mathrm{e}-03$ & $4.509 \mathrm{e}-04$ & 0.000 \\
\hline Terraced ${ }^{* * *}$ & $2.476 \mathrm{e}-03$ & $1.660 \mathrm{e}-04$ & 0.000 \\
\hline Semi Detached*** & $6.366 \mathrm{e}-03$ & $1.934 \mathrm{e}-04$ & 0.000 \\
\hline Detached $^{* * *}$ & $9.942 \mathrm{e}-03$ & $1.928 \mathrm{e}-04$ & 0.000 \\
\hline \multicolumn{4}{|l|}{ Socio-demographic variables: } \\
\hline Density_hab.km²*** & $3.302 \mathrm{e}-04$ & $9.290 \mathrm{e}-06$ & 0.000 \\
\hline Under_15_Years & $1.076 \mathrm{e}-03$ & $3.085 \mathrm{e}-04$ & 0.000 \\
\hline Unemployed & $-3.477 \mathrm{e}-03$ & $6.639 e-04$ & 0.000 \\
\hline Inactive_Retirees_Annuitants & $-1.366 \mathrm{e}-03$ & $2.192 \mathrm{e}-04$ & 0.000 \\
\hline \multicolumn{4}{|l|}{ Tertiary } \\
\hline \multicolumn{4}{|l|}{ Building variables: } \\
\hline Administration ${ }^{* * *}$ & $3.744 \mathrm{e}-02$ & $3.145 \mathrm{e}-03$ & 0.000 \\
\hline Services \& Miscellaneous (EIA \& Water) ${ }^{* * *}$ & $4.250 \mathrm{e}-01$ & $1.029 \mathrm{e}-02$ & 0.000 \\
\hline Banks_Insurance_Business ${ }^{* * *}$ & $1.480 \mathrm{e}-01$ & $6.694 \mathrm{e}-03$ & 0.000 \\
\hline Commerce $^{* *}$ & $4.606 \mathrm{e}-03$ & $6.804 \mathrm{e}-04$ & 0.000 \\
\hline Culture_Sport \& Other Services*** & $1.192 \mathrm{e}-02$ & $6.619 e-04$ & 0.000 \\
\hline Education ${ }^{* * *}$ & $6.589 e-02$ & $4.107 e-03$ & 0.000 \\
\hline Health Care \& Hospital ${ }^{* * *}$ & $1.393 \mathrm{e}-01$ & $7.125 e-03$ & 0.000 \\
\hline Transport \& Communication ${ }^{* * *}$ & $4.434 \mathrm{e}-01$ & $2.264 \mathrm{e}-02$ & 0.000 \\
\hline \multicolumn{4}{|l|}{ Socio-demographic variables: } \\
\hline Density $\left(\mathrm{hab} / \mathrm{km}^{2}\right)^{* * *}$ & $7.866 \mathrm{e}-05$ & $1.175 \mathrm{e}-05$ & 0.000 \\
\hline Wholesale_retail_warehousing_Restaurant*** & $9.782 \mathrm{e}-03$ & $7.496 \mathrm{e}-04$ & 0.000 \\
\hline Other Services* & $-2.199 \mathrm{e}-03$ & $3.469 \mathrm{e}-03$ & 0.526 \\
\hline \multicolumn{4}{|l|}{ Industrial } \\
\hline \multicolumn{4}{|l|}{ Building variables: } \\
\hline Food ${ }^{* * *}$ & 0.391097 & 0.015865 & 0.000 \\
\hline Other Industry ${ }^{* * *}$ & 0.122083 & 0.003106 & 0.000 \\
\hline Chemistry $^{* * *}$ & 0.065609 & 0.006236 & 0.000 \\
\hline Metal Fabrication ${ }^{* * *}$ & 0.180698 & 0.016154 & 0.000 \\
\hline Non-Metallic Minerals ${ }^{* * *}$ & 0.104405 & 0.010338 & 0.000 \\
\hline Steel Non-Ferrous* & 0.129739 & 0.054939 & 0.01823 \\
\hline Textile \& Paper*** & 0.092746 & 0.010760 & 0.000 \\
\hline \multicolumn{4}{|l|}{ Socio-demographic variables: } \\
\hline Manufacturing \& Mining Extractive*** & 0.006205 & 0.002141 & 0.00376 \\
\hline Construction** & 0.011317 & 0.003680 & 0.00211 \\
\hline
\end{tabular}

Table 8

Change rate of the EC used in heating residential and tertiary buildings between 2012 and future horizon (2030, 2040, and 2050).

\begin{tabular}{lll}
\hline Period & $\begin{array}{l}\text { Heating EC change rate } \\
\text { for residential buildings }\end{array}$ & $\begin{array}{l}\text { Heating EC change rate } \\
\text { for tertiary buildings }\end{array}$ \\
\hline $2012-2030$ & $-6.34 \%$ & $-7.19 \%$ \\
$2012-2040$ & $-7.01 \%$ & $-7.94 \%$ \\
$2012-2050$ & $-8.82 \%$ & $-10.00 \%$ \\
\hline
\end{tabular}

Table 9

Change rate of the EC used in cooling for tertiary buildings between 2012 and future horizon (2030, 2040, and 2050).

\begin{tabular}{lc}
\hline Period & Cooling EC change rate on a regional scale \\
\hline $2012-2030$ & $8.28 \%$ \\
$2012-2040$ & $10.24 \%$ \\
$2012-2050$ & $11.94 \%$ \\
\hline
\end{tabular}

ing sector was estimated by $\mathrm{m}^{2}$ for each industrial building category and in the model, it is explained by $38.55 \%$ (Fig. 7). The construction activity in the industrial sector has the highest impact on electricity consumption. No clear relationship was found between building age and size in many studies. Building variables played important role in electricity consumption, except for building size [11].

Regarding the impact of socio-demographic variables, they explained EC lesser than building variables. The socio-demographic model explained $61.59 \%$ of EC for residential buildings, $26.34 \%$ for tertiary buildings and $3.41 \%$ for industrial buildings. Regarding the household composition, the presence of under 15 years increases significantly the EC in the household contrary to the findings in the previously reported paper by Brounen et al. [10] and Jones et al. [16]. Differences in the sample, of various studies, might explain these differences in output regarding the effect of household composition. Gilg et al. and Smallbone found that higherincome relates positively to appliances ownership and thus increase EC of household $[49,50]$. However, others argue that income might have simply been inaccurate and not reflect actual behaviour and lifestyles, any impact might be too small to be picked up in EC, or finally, there might be other mediating variables (beyond income) $[9,23,33]$. In our study, the employed and unemployed variables were highly related, hence creating an issue of collinearity. Thus the employed variable coefficient was set to zero through Lasso regression and removed in the final model. As the number of unemployed in the residential buildings sector increases, the EC decreases which may be explained by the need to making the economy and lack of consuming types of equipment.

The $\beta$ OLS coefficients from the final regression show that the annual EC in a statistical sector for residential buildings sector increases by an average of $1.0097 \mathrm{GWh}$ for detached buildings class, followed by $1.006 \mathrm{GWh}$ for semi-detached, $1.002 \mathrm{GWh}$ for terraced and $1 \mathrm{GWh}$ for an apartment when moving from a one to two households for a specific building class. When increasing by one unit building in the tertiary buildings sector, transport and communication activities have the higher increase by 1.558 GWh in annual EC, banks by 1.160 GWh and hospitals by 1.150 

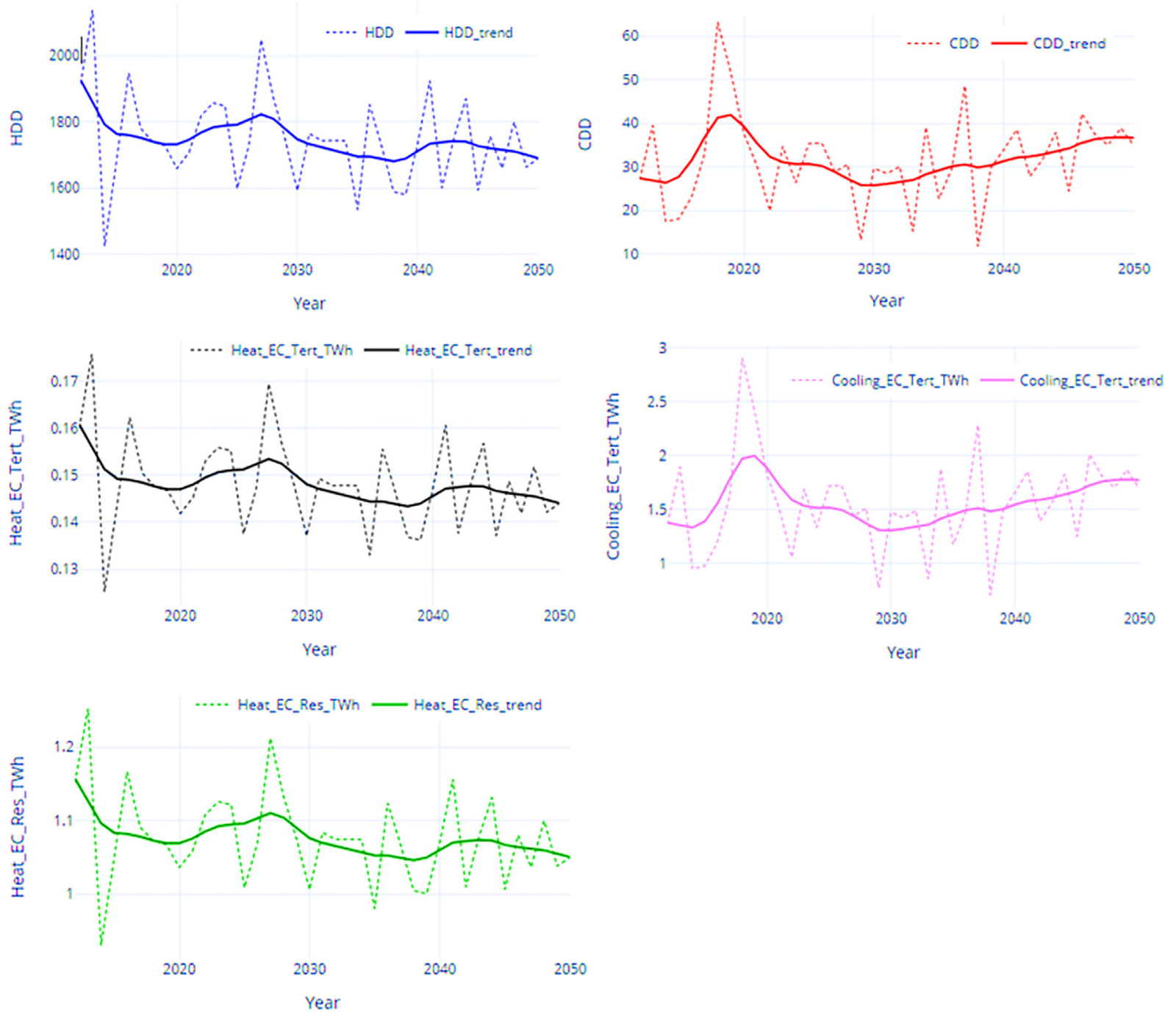

Fig. 8. Predicted HDD, CDD, HEC (Heat_EC_Tert_TWh), CEC (Cooling_EC_Tert_TWh) in tertiary buildings and HEC (Heat_EC_Res_TWh) in residential buildings, and from 2012 to 2050 .

GWh, energy and water treatment facilities by 1.530 GWh. On the other hand, food increases by $1.479 \mathrm{GWh}$ and metal fabrication by 1.198 GWh respectively for a one-unit increase in the industrial buildings sector (Table 7). When looking at socio-demographic variables, the increase by one person in population density per $\mathrm{km}^{2}$ is about $0.00033 \mathrm{GWh}$ annual EC on average in the residential buildings. To summarize, a total of $70.86 \%$ for residential buildings, $54.33 \%$ for tertiary buildings and $39.75 \%$ for industrial buildings of the variability in annual EC was explained by the two classes of predictors (building and socio-demographics variables) (Fig. 7). On the other hand, the projected increase in EC for cooling in the tertiary building sector from 2012 to 2050 is $11.94 \%$ on a regional scale (Table 9). This increase follows the trend of the predicted regional CDD of $14.04 \%$ while the HDD will decrease by $-11.76 \%$ at the same period interval. However, the increase in CDD is more severe for the building stock of southern countries of Europe (Spain, Italy and Greece) where the projected value is greater than $40 \%$ by the end of the 21 st century [ 48 ] but take into consideration that these countries have a warm climate compared to Belgium. The general increase pattern in CDD and decrease in HDD-related cooling and heating EC is a clear effect of climate change on the building sector [51].

\subsubsection{Implications of the statistical analysis findings}

The results imply that appliances ownership and usages are the most important variables explaining residential and tertiary electricity use. Socio-demographic information does add explanatory power to the models but the building only model already explains $66.46 \%$ and $50.53 \%$ for residential and tertiary respectively. The study was conducted at the statistical sector level, and the resulting models highly explained the variability of EC. Therefore, the future policy development for buildings EC must prioritize the improvement of energy efficiency of appliances. In general, progress has been done with product potential energy saving by labelling like the EU energy efficiency label.

However, further research should aim at understanding better what drives the choice and usage of appliances. This need is more important nowadays than before with the lock down procedure due to the coronavirus pandemic, which forces changes in everyday lifestyle and behaviours. The use of household electricity appliances has to be controlled and regulated. Increasing EC associated with appliances usages, for example, hours of watching TV, has been linked to many health issues like childhood obesity [52,53] and greater risk of type 2 diabetes and cardiovascular disease in adults [54,55]. Hence, a joint campaign from different disciplines 

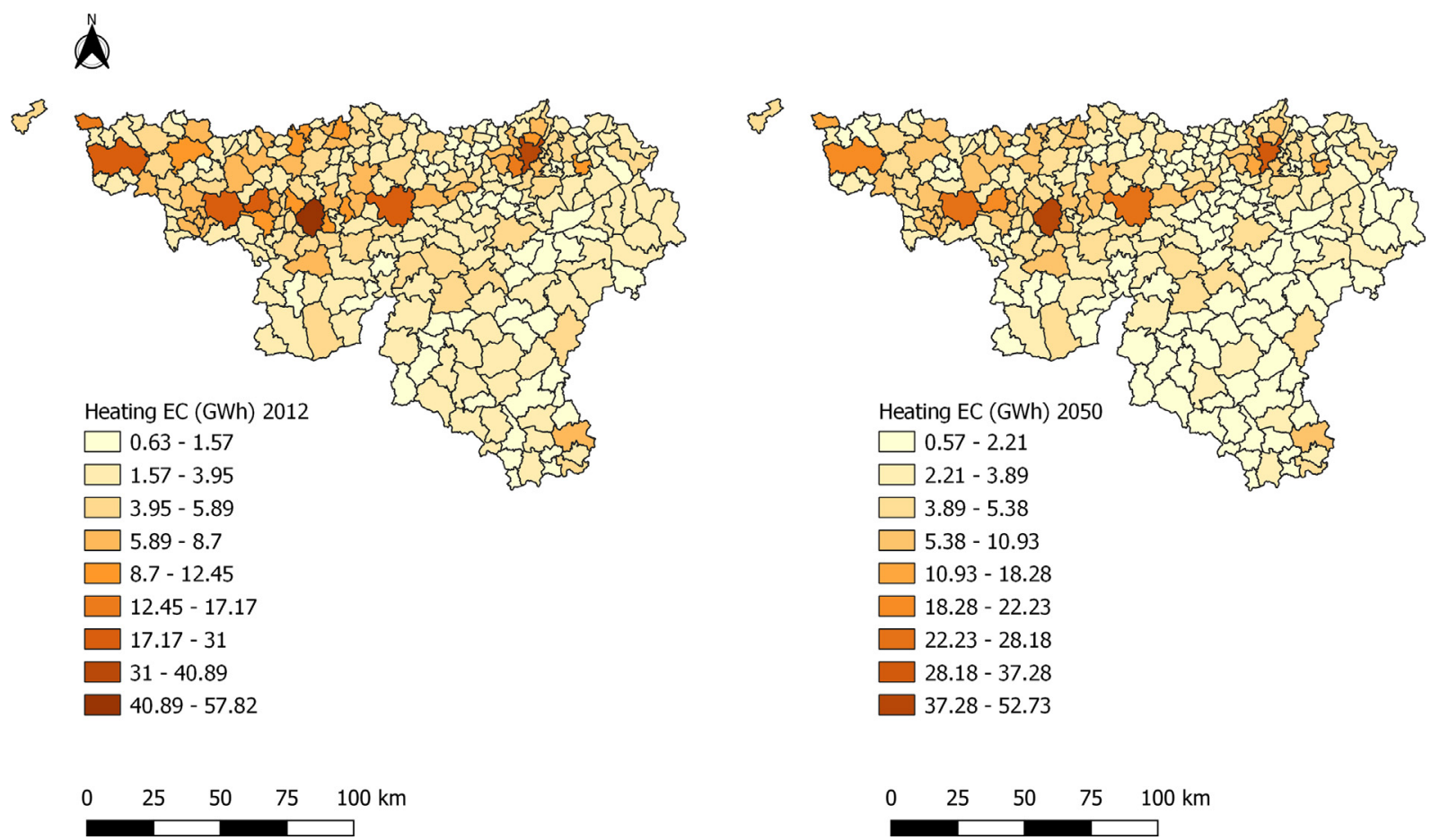

Fig. 9. Electricity used in heating for residential buildings in 2012 (left) and its projection in 2050 (right) on municipality scale.

\section{$\Delta$}
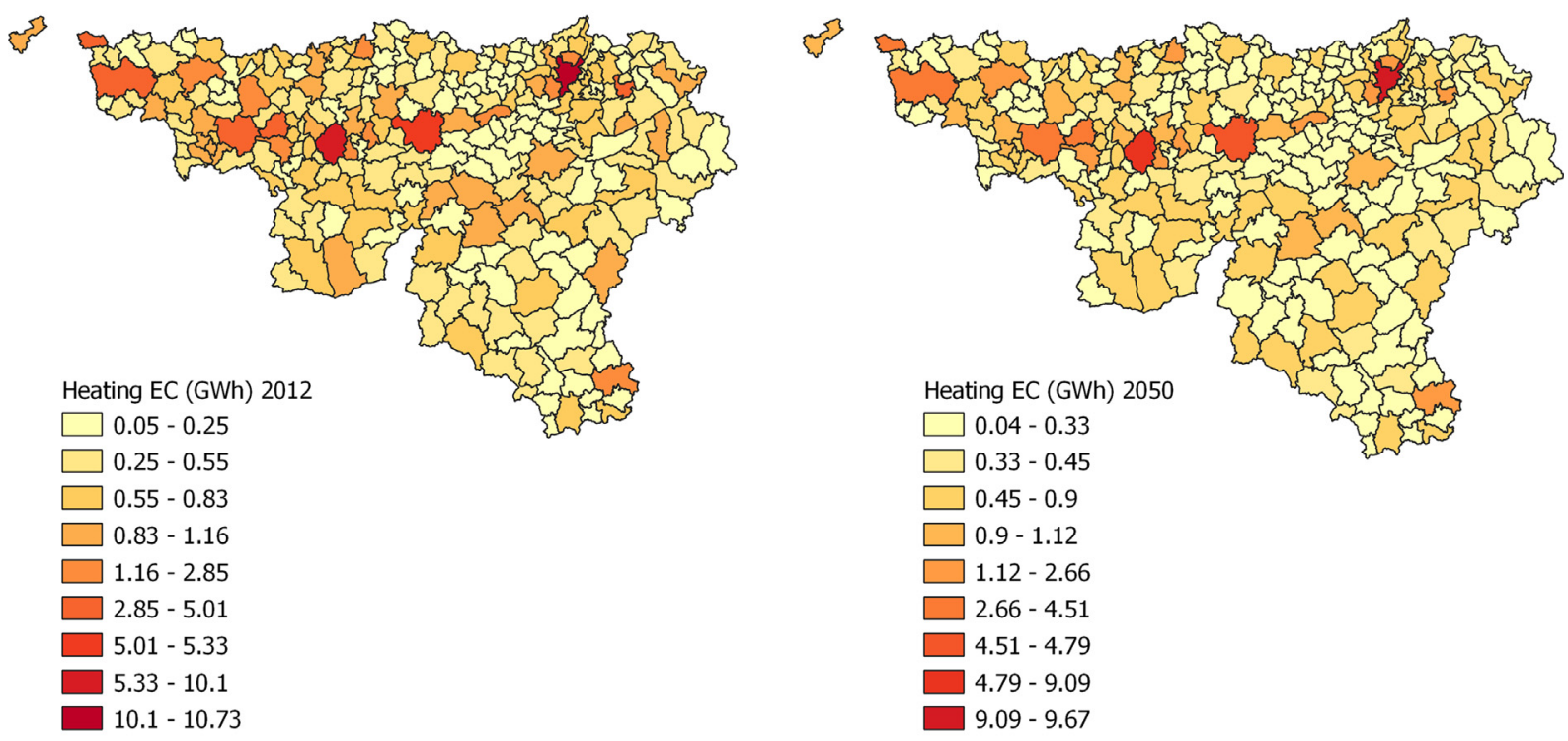

$\begin{array}{lllll}0 & 25 \quad 50 \quad 75 \quad 100 & \mathrm{~km}\end{array}$

$\begin{array}{lllll}0 & 25 \quad 50 \quad 75 \quad 100 & \mathrm{~km}\end{array}$

Fig. 10. Electricity used in heating for tertiary buildings in 2012 (left) and its projection in 2050 (right) on municipality scale.

tackling TV use would have multiple beneficial outcomes. Moreover, some technics to reduce EC for households should be promoted. For instance, encouraging outdoor clothes drying or internal shared drying rooms to avoid regular usage of a tumble dryer. Finally, on the dwelling level, the benefit of terraced houses is remarkable in terms of heating in winter and cooling in summer. This type of construction has to be promoted in smart city development programs to increase the EC efficiency of the building stock, especially for regions like Wallonia where the building stock is dominated by detached houses $[40,41]$. 

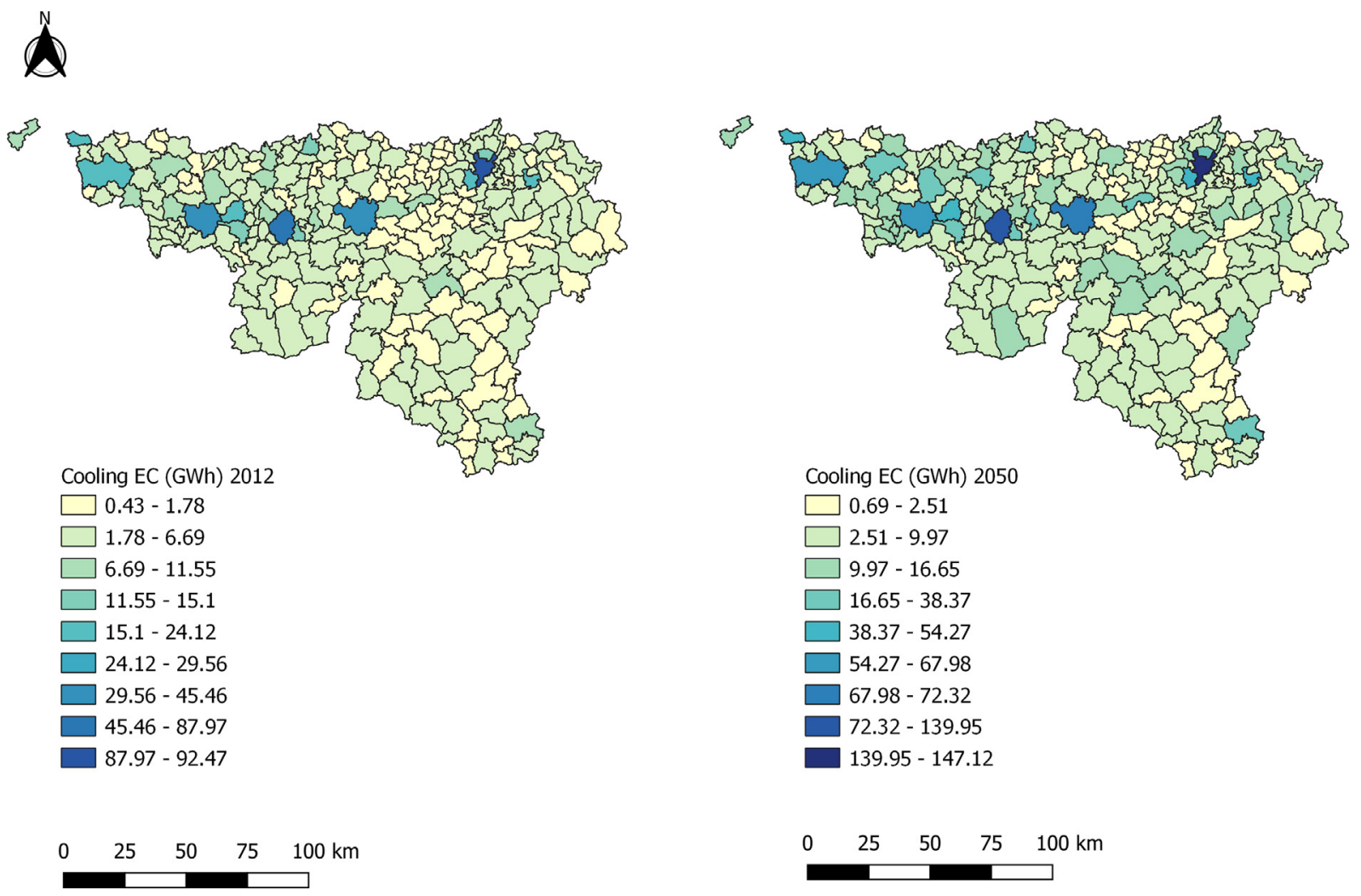

Fig. 11. Cooling EC spatialization on municipality scale. The classification used 9 classes both in 2012 and in 2050 and the type of classification used is natural breaks of Jenks.

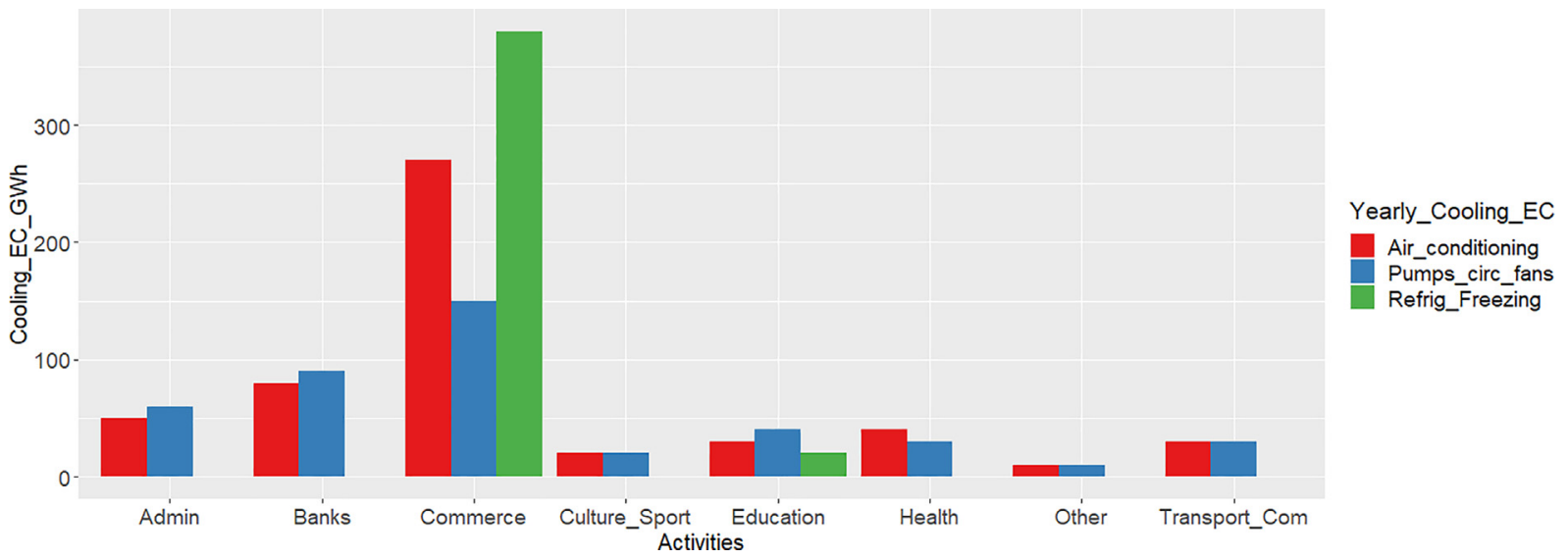

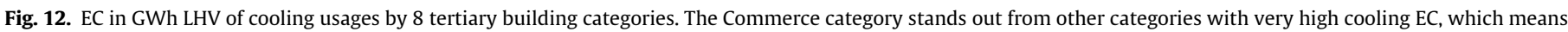
that cooling is very important in that category.

\subsection{EC mapping}

EC is mapped on 3 territorial scales, namely SS (the smallest), municipality and province scales. On the SS scale, the annual average EC of the residential, tertiary and industrial sectors are shown in Fig. 13, Fig. 14 and Fig. 15 respectively.

\subsubsection{Statistical sector scale}

Generally, the yearly average EC on the SS scale for both residential, tertiary and industrial sectors is the highest in dense and/or main cities.

For the residential sector, only 199 SS don't have any house and the annual EC at the SS scale varies between 0.004 and 8.66 GWh
LHV. In rural areas, the EC is low, certainly because they are sparsely populated (Fig. 13). In the tertiary sector, the yearly average EC at the SS scale is not uniformly distributed and it varies between 0.005 and 22.29.78 GWh LHV. 1049 SS don't have any tertiary building and, alike the residential sector, many activities are located in main cities. The EC of tertiary buildings at the SS scale is the highest in city centres (Fig. 14). Regarding the industrial sector, there are around 3358 SS that don't have any industrial buildings. The yearly average EC of industrial buildings at the SS scale varies between 0.0004 and 873.77 GWh LHV. The industrial sector is the most consuming. Many industries are located in Charleroi, Liège, Seraing and Jemeppe-sur-Sambre, and thus those parts have the highest EC (Fig. 15). 


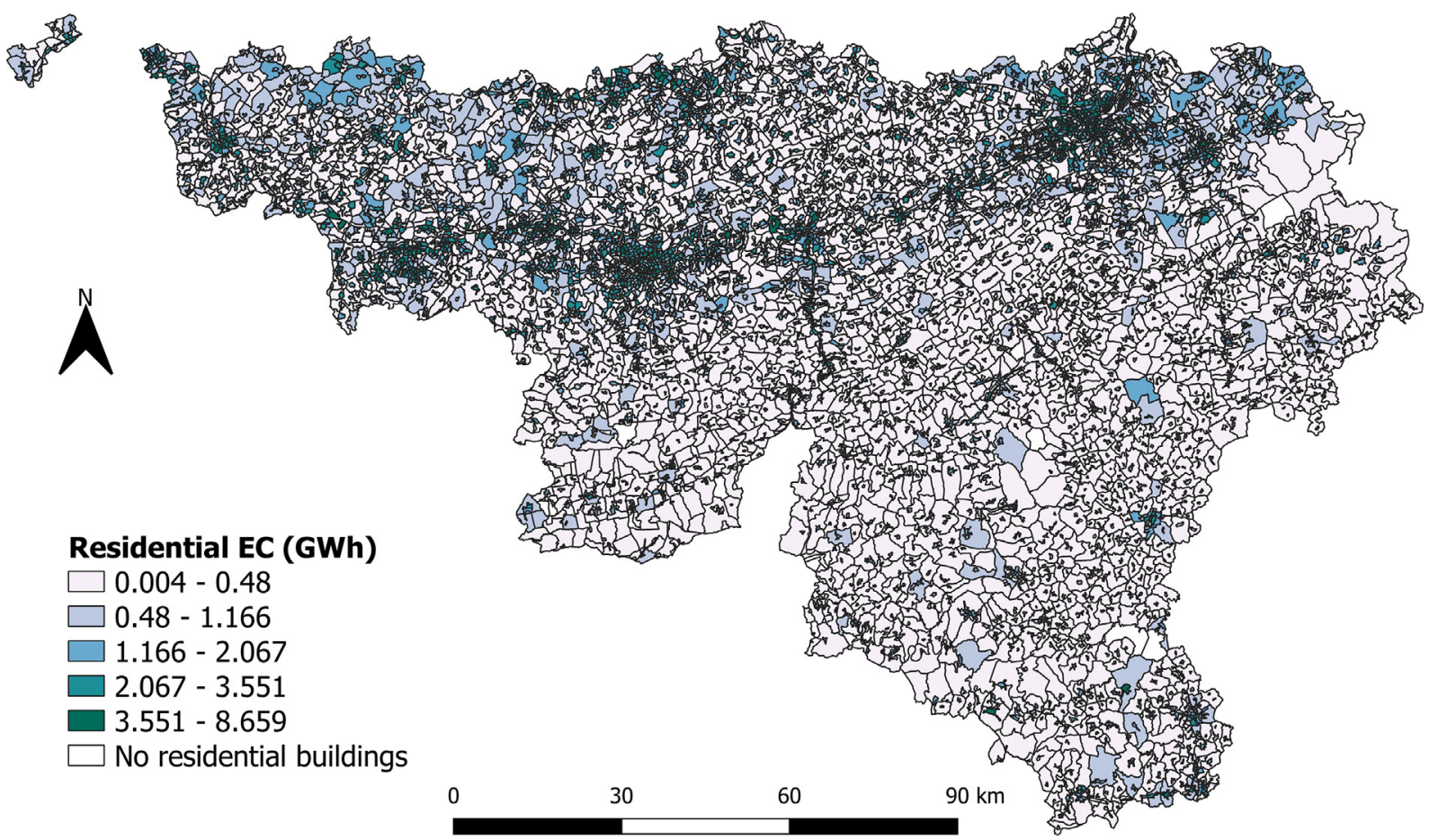

Fig. 13. Annual average EC in GWh LHV of the residential sector on a statistical sector scale. The symbology used graduated colours with natural breaks of Jenks for classification.

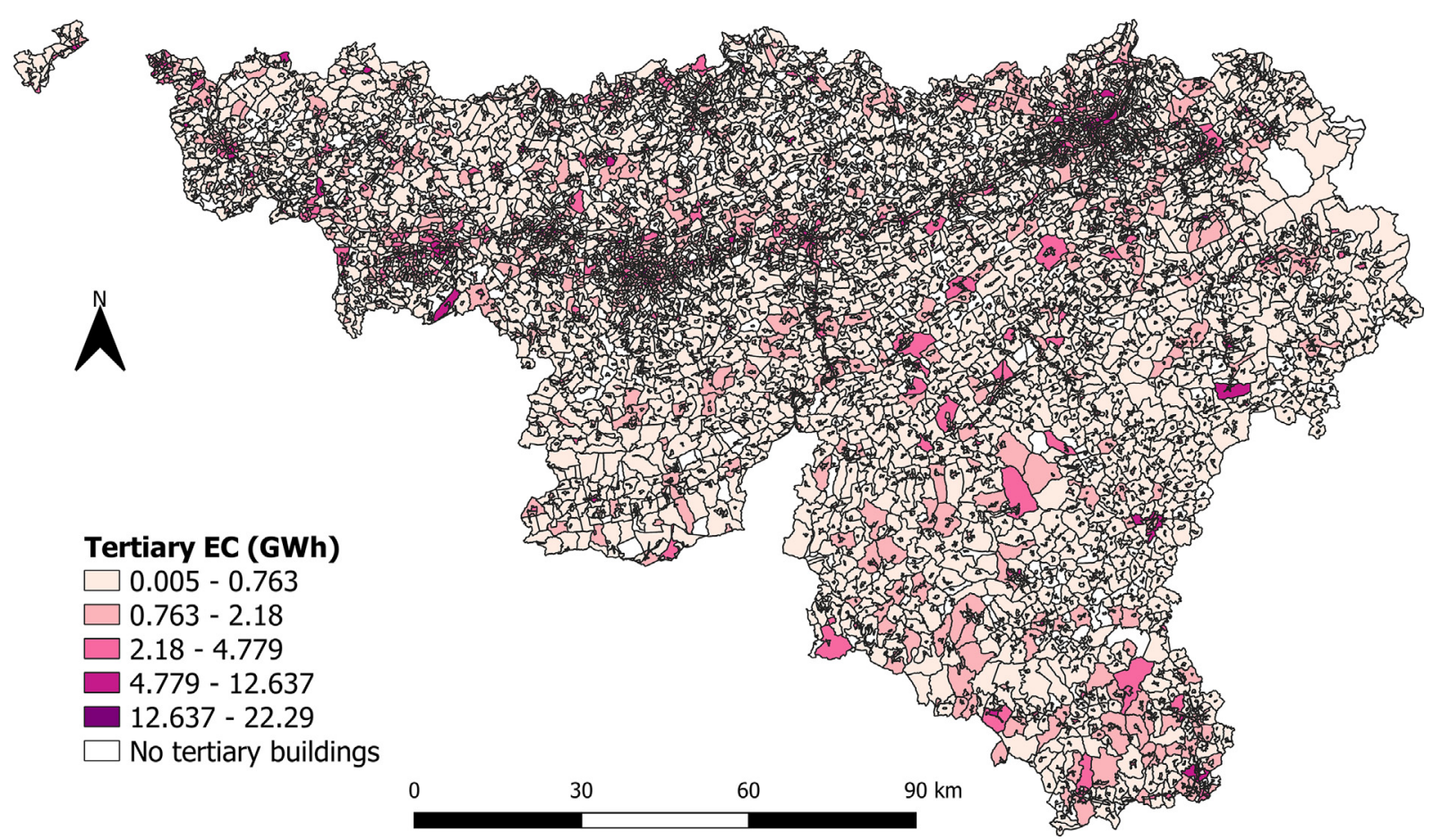

Fig. 14. Annual average EC in GWh LHV of tertiary buildings on a statistical sector scale. The symbology used graduated colours with natural breaks of Jenks for classification.

\subsubsection{Municipality scale}

The spatialization on the municipality scale shows the municipalities to focus on terms of reducing the EC in buildings or improve the way of consumption. 2 municipalities (Charleroi and Liège) which are the biggest Walloon cities have the highest EC related to residential and tertiary sectors. In the industrial sector, the highest EC is seen in Charleroi (Fig. 16). The rural municipalities have lower EC, whereas the main cities are more densely populated and thus have higher EC. The highest yearly average EC at the municipality scale goes to $371.43 \mathrm{GWh}$ LHV for the residential sector, which is higher compared to tertiary where it goes to 343.53 GWh LHV but significantly below EC in the industrial sector 


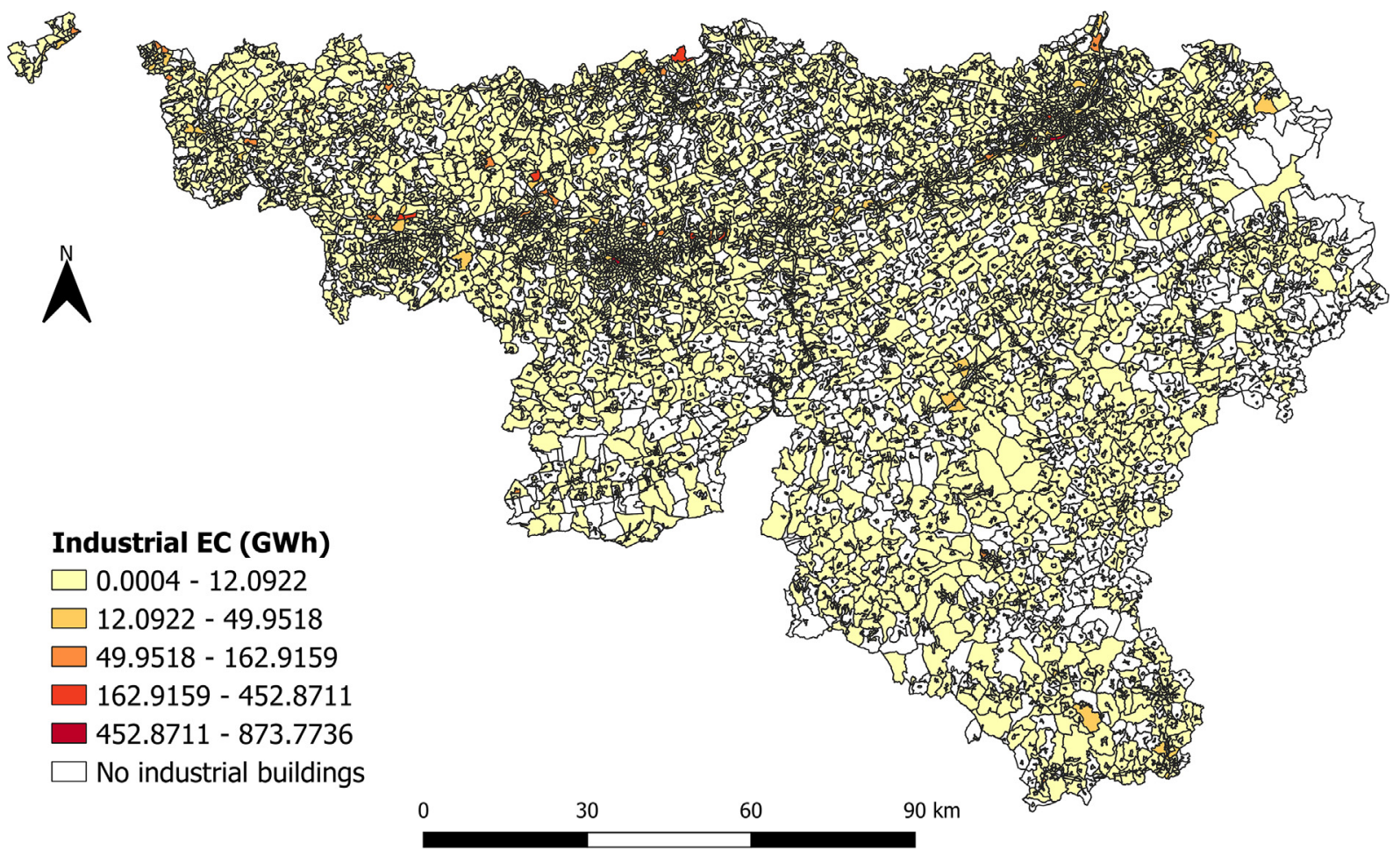

Fig. 15. Annual average EC in GWh LHV of industrial buildings on a statistical sector scale. Also, the symbology used graduated colours with natural breaks of Jenks for classification.

Table 10

Residential, tertiary and industrial EC values in GWh LHV and their corresponding number of buildings in a province.

\begin{tabular}{|c|c|c|c|c|c|c|}
\hline Province & Residential EC (GWH LHV) & Tertiary EC (GWH LHV) & Industrial EC (GWH LHV) & Residential NB & Tertiary NB & Industrial NB \\
\hline Brabant Wallon & 705.91 & 434.41 & 696.15 & 151,763 & 10,945 & 3051 \\
\hline Hainaut & 2776.57 & 2133.63 & 5549.19 & 611,560 & 52,779 & 16,777 \\
\hline Liège & 1953.98 & 1670.19 & 2821.00 & 427,760 & 43,300 & 11,095 \\
\hline Luxembourg & 547.18 & 704.91 & 500.33 & 117,127 & 21,666 & 3641 \\
\hline Namur & 936.42 & 886.87 & 1168.98 & 201,487 & 28,515 & 5172 \\
\hline
\end{tabular}

\section{ه}

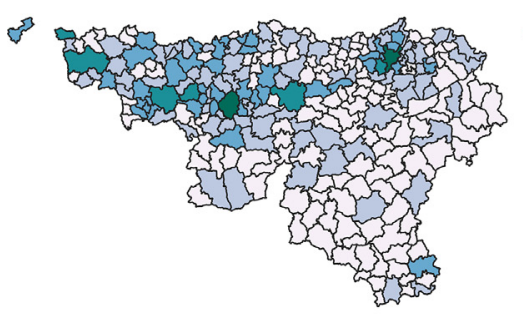

Residential EC (GWh)

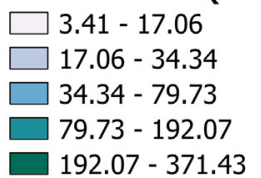

$0 \quad 30 \quad 60 \quad 90 \mathrm{~km}$

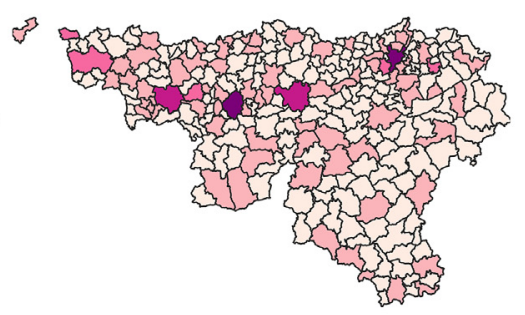

Tertiary EC (GWh)

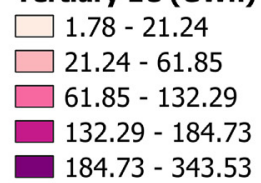

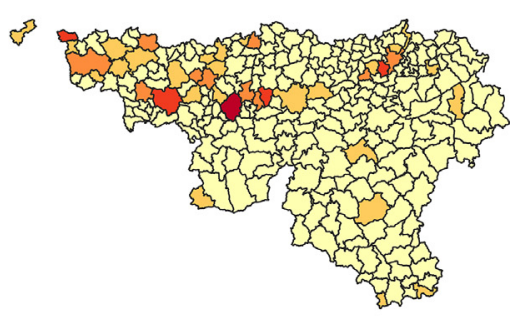

Industrial EC (GWh)

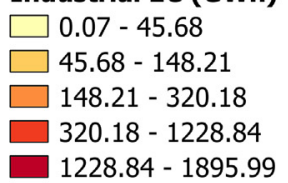

Fig. 16. On municipality scale, the annual average EC in GWh LHV is presented for residential (left), tertiary (middle) and industrial (right) buildings. 


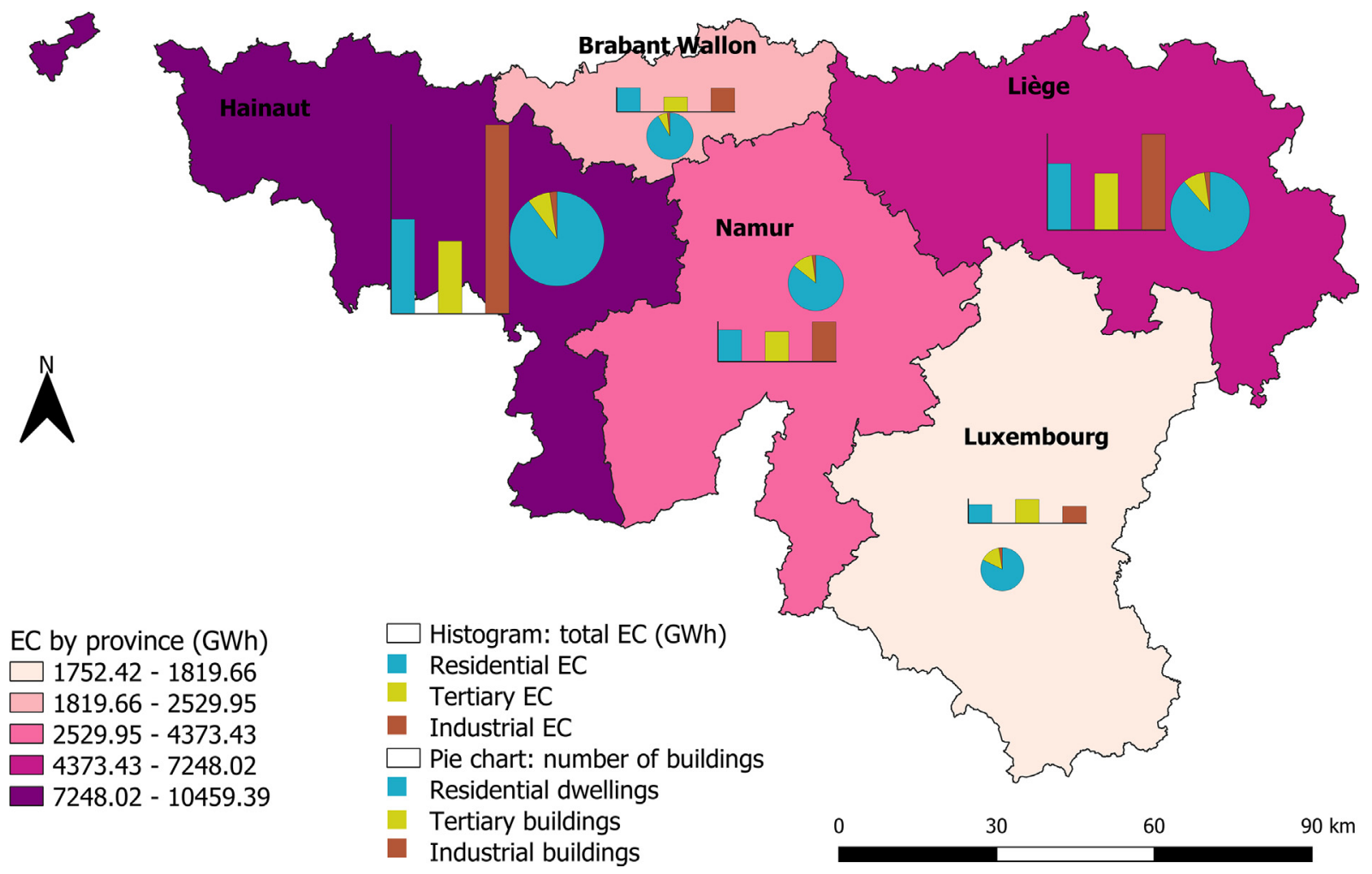

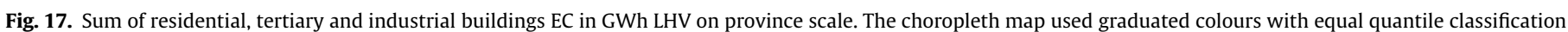

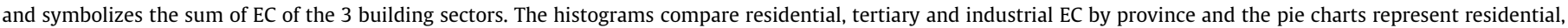
tertiary and industrial buildings in a province.

where it goes to 1895.99 GWh LHV at the municipality scale. The industries are very consuming compared to residential and tertiary activities.

\subsubsection{Province scale}

Table 10 summarizes the results shown in Fig. 17. Although the residential sector has many buildings in each province, it is the sector with lower EC at this scale. One province distinguishes itself from the others: Hainaut province has the highest number of buildings in each building sector, and subsequently, it has the highest yearly average EC see (Fig. 16 Fig. 17).

The graduated colours illustrate the yearly average EC by each province. The histograms represent the sum of EC of all building sectors (residential, tertiary and industrial) by province and the pie charts indicate the sum of the number of all building sectors by province. The industry buildings have higher EC even though the number of buildings is low. The priority measures to reduce EC in industrial buildings or think of innovative technologies which could reduce their consumption should be taken in Hainaut, then Liège The southern-east province, Luxembourg, has a lower number of buildings in each sector, and thus lower EC.

Table 11

Comparing the EC estimated in this study with the values given in ICEDD reports for each building sector. The relative difference obtained with the complete building stock model is very low, thus the obtained results are accurate and are validated.

\begin{tabular}{lccc}
\hline & EC Cadastral, this & EC ICEDD (TWh) & Relative difference (RD) \\
& study (TWh) & & \\
\hline Residential & 6.92 & 6.78 & $2.02 \%$ \\
Tertiary & 5.83 & 5.84 & $-0.17 \%$ \\
Industrial & 10.74 & 10.73 & $0.09 \%$ \\
\hline
\end{tabular}

\subsection{Comparison with other studies}

The results obtained in this study are compared to the yearly EC given in the ICEDD reports $[40,41]$, Table 11 and the Walstat indications [56], Table 12 .

In Table 11, the relative difference (RD) between the obtained results and the values given in the ICEDD report indicates that the yearly average EC of the Walloon building stock based on detailed cadastral data has been increased by $2.02 \%$ for the residential sector compared to regional report, has been reduced by $-0.17 \%$ in the tertiary sector and has been increased by $0.09 \%$ in

Table 12

Comparison of the total annual EC (residential, tertiary and industrial buildings) with the ICEDD values and the Walstat indicators on a regional scale.

\begin{tabular}{llr}
\hline & Total EC (TWh) regional scale & RD \\
\hline This study (2012 data) & 23.49 & \\
ICEDD (2012 data) $[38,39]$ & 23.35 & $0.59 \%$ \\
Walstat (2012 data) $[53]$ & 23.79 & $-1.29 \%$ \\
\hline
\end{tabular}

Table 13

Comparison of estimated EC in residential housing with the value given in ICEDD reports. Also, the relative difference obtained is low, which allows us to validate the obtained results.

\begin{tabular}{llll}
\hline & EC Cadastral $(\mathrm{kWh})$ & EC ICEDD $(\mathrm{kWh})$ & RD \\
\hline Apartment & 4292.15 & 4453 & $-3.75 \%$ \\
Terraced house & 4366.03 & & $-1.99 \%$ \\
Semi-detached house & 4515.81 & & $1.39 \%$ \\
Detached house & 4860.18 & & $8.38 \%$ \\
\hline
\end{tabular}


the industrial sector. Whereas in Table 12, the total annual EC of our study is 23.49 TWh which is acceptable compared to the ICEDD and Walstat values (23.35 TWh and 23.79 TWh respectively) on the regional scale. The relative differences are very low which allows the validation of this study's results.

In Table 13, the calculated EC in different residential buildings is compared to the annual average EC given by ICEDD which is the average of one residential housing. The RD is acceptable and supports the validation of the calculated EC (see Table 12 and Table 13).

\subsection{Limitations of the study and recommendations}

The need for the authors to assess the electricity consumption (EC) of the regional building stock is challenging both on statistical and technical points. This study presents an innovative and simplified methodology to calculate and forecast the EC for residential housing, tertiary and industrial buildings based on the available data for each building sector, at regional scale, which allows municipalities, policy makers and inverters to take clear mitigation or direct measures at the city level. Such actions are not feasible when the research is limited at one or a couple of buildings as found in many literatures. However, working at a larger scale has its own consequences. The level of data confidentiality especially in industrial sector is high. Moreover, investigating each individual building could take an unimaginable amount of time considering that the Wallon Region has over 1.7 million buildings. The independent parameters used in the EC model were selected depending to the data availability. For the moment, the usages EC were not given in the ICEDD nor in any other reports, thus the authors recommend in further works to investigate this issue in the industrial building sector. In addition, considering physical mechanisms could be very interesting if these are available for a whole building stock to be integrated in the model. However, the maps are created at the statistical sector, municipal, and province levels, which makes the regional average values used sufficiently representative of real EC. This research reached valuable and pertinent findings at regional level and allowed to make important conclusions using calculated annual EC and socio-demographic variables for residential, tertiary and industrial buildings sectors.

Although the building models performed well, the sociodemographic explanatory power was limited. This raises the question about other factors that determine EC that was not considered in this study. Some data are hard to measure and others have a smaller effect on EC to be analysed [15]. For example, the number of heated swimming pools, days of vacation taken away from the house, etc. Moreover, remarkable progress has been made to solve these problems. More recent technology such as using smartmeter to measure hourly EC in the building might overcome these limitations and help better understanding of electricity use. In addition, predicting EC for tertiary building sector up to 2050 horizon should consider measured hourly or daily EC data from smart metres for prediction using only real measured data.

The cooling and heating (EC) of buildings depends not only on temperature but also on building characteristics, household composition, consumer habit, electrical equipment, etc. [22,24,57,58]. Data scarcity and difficulties to measure some of these parameters are the principal challenges related to the development of the models. During this study, the authors investigated the impact of climate change on the trend of the EC used in heating for residential housings and EC used for heating and cooling for tertiary buildings to the 2050 horizon. The heating and cooling of buildings are strongly related to the weather parameters such as temperature. The temperature-related model shows higher precision in predicting the EC in buildings at the statistical sector level. However, the authors recommend including additional parameters (exogenous variables) such as buildings 'renovation, renovation rate, electrical equipment, working days, etc. in the cooling and heating EC prediction model.

\section{Conclusion and outlooks}

Using a large regionally cadastral database of more than $1,700,000$ buildings, this study showed that appliances ownership and usages are the most influential variables in understanding the EC of the residential and tertiary Walloon building stock, including buildings with electric heating and cooling systems. However, in the industrial building sector, the understanding of EC is based on building size. Hence, to reduce the EC, energy-efficient appliances ought to become more and more widespread. Firstly, in this study, the EC is assessed separately depending on the building sector (residential, tertiary and industrial buildings) using the topdown approach and then aggregated on different territorial scales (statistical sector, municipality, urban region and province) using the bottom-up approach. Furthermore, the results from the topdown and bottom-up approaches are spatialized using QGIS software. Based on the maps' visualizations, the higher EC on municipality scale was found in large and main cities for residential and tertiary buildings, but for industrial buildings, the higher EC is mostly found in the outskirts of the cities. For example, the higher EC by municipality scale varies from 3.41 to 371.43 GWh LHV for residential buildings, from 1.78 to 343.53 GWh LHV for tertiary buildings and from 0.07 to 1895.99 GWh LHV for industrial buildings. The lower EC is found in small villages.

During the statistical analysis, the building variables played a greater role than socio-demographic variables. For example, the study found that a one-unit increase of apartments in the statistical sector increases the annual EC by $1 \mathrm{GWh}$ whereas the increase by one person in population density per $\mathrm{km} 2$ increases the annual EC by 0.00033 GWh on average in the residential buildings. Though, depending on data availability, the outcome might vary from one research study to the other. In addition, demographic variables such as unemployed, under 15 years and population density played hardly a role in understanding the EC. Employed and unemployed variables had multicollinearity and consequently, one variable namely employed was removed from the final model. This part of the study has important methodological implications such as checking for and addressing multicollinearity which is crucial in performing regression analysis.

In addition, predicting the evolution of EC in existing buildings using the heating and cooling degree-days, help set adaptive responses and policies to the global climate change. The prediction process considered the temperature data from 1901 to 2019 to predict temperature up to 2050 using an artificial intelligence model GRU, then calculating HDD and CDD using UK-Met Office equations. Afterwards, the EC used for heating and cooling is assessed using energy equations to predict until 2050. This study found that the HDD will decrease by $-11.76 \%$ while the CDD will increase by $14.04 \%$ for the 2050 horizon on a regional scale. In addition, the EC used for cooling will increase by $11.94 \%$ in 2050 in tertiary buildings whereas the EC used in heating for the residential and tertiary buildings will decrease from $-6.34 \%$ to $-8.82 \%$ and $-7.19 \%$ to $-10 \%$ on a regional scale respectively. Applied to the smart cities development to reduce emissions from buildings EC, these decisions might differ depending on these predictions and also use the produced maps to see well which area to focus on to reach European goals in terms of buildings energy consumption reduction.

This study used replicable methodologies which can be applied in other regions of the world, based on the availability of the data. 
Following this study, dynamic modelling which is hourly energy consumption will be performed and validated using smart measured data in real-time. In addition, realistic and regulatory scenarios will be established as well as multi-criteria decision aiding tools, based on these scenarios, developed to see and select the best energy management strategies at the regional scale.

Data availability

- The energy regional reports can be found on: https://energie. wallonie.be/fr/bilans-energetiques-wallons.html?IDC=6288

- The Wallonia cadastral database used to conduct this study is confidential and cannot be shared. However, the data can be obtained under convention agreements over the SCIP (Structure de Coordination de l'Information Patrimoniale): https://www. scip-cspi.be/fr

- The temperature data are retrieved from: https://www.ncdc. noaa.gov/

- The Wallonia shapefiles can be accessed via: https://geoportail. wallonie.be/home.html

\section{Funding sources}

This research, which is part of Wal-e-cities projects, is financed by the European Regional Development Fund (ERDF) and the Wallonia Region of Belgium.

\section{CRediT authorship contribution statement}

Antoinette Marie Reine Nishimwe: Literature review; Data collection and correction; Methodology; Software - programming and mapping; Analysis and discussion; Writing - Original draft preparation. Sigrid Reiter: Supervision; Correction; Validation of methodologies; Writing - Revision of final draft.

\section{Declaration of Competing Interest}

The authors declare that they have no known competing financial interests or personal relationships that could have appeared to influence the work reported in this paper.

\section{Acknowledgements}

The authors acknowledge the European Regional Development Fund (ERDF) and the Walloon Region of Belgium, which financed the Wal-e-cities projects. Also, thanks to the LEMA research team of the University of Liège where this study is conducted.

\section{References}

[1] M, Cornet, J Duerinck, E. Laes, P. Lodewijks, E. Meynaerts, J. Pestiaux, et al. Scenarios for a Low Carbon Belgium by 2050. 2013.

[2] National Climate Commission. Belgium's fourth biennial report on climate change - Under the United Nations framework convention on climate change. 2020.

[3] L. Waters, V. Goodright, E. Wilkes, Domestic energy consumption in the UK between 1970 and 2014. vol. 3. 2015.

[4] M. Bedir, E. Hasselaar, L. Itard, Determinants of electricity consumption in Dutch dwellings, Energy Build. 58 (2013) 194-207, https://doi.org/10.1016/j. enbuild.2012.10.016.

[5] K. Fabbri, V. Tarabusi, Top-down and Bottom-up Methodologies for Energy Building Performance Evaluation at meso-scale Level - A Literature Review, Am. J. Civ. Eng. Archit (2014).

[6] S.-M. Hong, G. Paterson, E. Burman, P. Steadman, D. Mumovic, A comparative study of benchmarking approaches for non-domestic buildings: Part 1 - Topdown approach, Int. J. Sustain. Built. Environ. 2 (2) (2013) 119-130, https://doi. org/10.1016/j.ijsbe.2014.04.001.

[7] E. Burman, S.-M. Hong, G. Paterson, J. Kimpian, D. Mumovic, A comparative study of benchmarking approaches for non-domestic buildings: Part 2 Bottom-up approach, Int. J. Sustain. Built. Environ. 3 (2) (2014) 247-261, https://doi.org/10.1016/j.ijsbe.2014.12.001.
[8] M. Kavgic, A. Mavrogianni, D. Mumovic, A. Summerfield, Z. Stevanovic, M. Djurovic-Petrovic, A review of bottom-up building stock models for energy consumption in the residential sector, Build. Environ. 45 (7) (2010) 16831697, https://doi.org/10.1016/j.buildenv.2010.01.021.

[9] G.M. Huebner, I. Hamilton, Z. Chalabi, D. Shipworth, T. Oreszczyn, Explaining domestic energy consumption - The comparative contribution of building factors, socio-demographics, behaviours and attitudes, Appl. Energy 159 (2015) 589-600, https://doi.org/10.1016/j.apenergy.2015.09.028.

[10] D. Brounen, N. Kok, J.M. Quigley, Residential energy use and conservation: Economics and demographics, Eur Econ Rev 56 (5) (2012) 931-945, https:// doi.org/10.1016/j.euroecorev.2012.02.007.

[11] O. Guerra Santin, L. Itard, H. Visscher, The effect of occupancy and building characteristics on energy use for space and water heating in Dutch residential stock, Energy Build. 41 (11) (2009) 1223-1232, https://doi.org/10.1016/j. enbuild.2009.07.002

[12] K. Steemers, G.Y. Yun, Household energy consumption: A study of the role of occupants, Build. Res. Inf. 37 (5-6) (2009) 625-637, https://doi.org/10.1080/ 09613210903186661.

[13] C. Bartusch, M. Odlare, F. Wallin, L. Wester, Exploring variance in residential electricity consumption: Household features and building properties, Appl. Energy 92 (2012) 637-643, https://doi.org/10.1016/j.apenergy.2011.04.034.

[14] K.J. Baker, R.M. Rylatt, Improving the prediction of UK domestic energydemand using annual consumption-data, Appl. Energy 85 (6) (2008) 475-482, https://doi.org/10.1016/j.apenergy.2007.09.004.

[15] D. Ndiaye, K. Gabriel, Principal component analysis of the electricity consumption in residential dwellings, Energy Build. 43 (2-3) (2011) 446453, https://doi.org/10.1016/j.enbuild.2010.10.008.

[16] R.V. Jones, K.J. Lomas, Determinants of high electrical energy demand in UK homes: Socio-economic and dwelling characteristics, Energy Build. 101 (2015) 24-34, https://doi.org/10.1016/j.enbuild.2015.04.052.

[17] A. Kavousian, R. Rajagopal, M. Fischer, Determinants of residential electricity consumption: Using smart meter data to examine the effect of climate, building characteristics, appliance stock, and occupants' behavior, Energy 55 (2013) 184-194, https://doi.org/10.1016/j.energy.2013.03.086.

[18] D. Wiesmann, I. Lima Azevedo, P. Ferrão, J.E. Fernández, Residential electricity consumption in Portugal: Findings from top-down and bottom-up models, Energy Policy 39 (5) (2011) 2772-2779, https://doi.org/10.1016/j. enpol.2011.02.047.

[19] P. Wyatt, A dwelling-level investigation into the physical and socio-economic drivers of domestic energy consumption in England, Energy Policy 60 (2013) 540-549, https://doi.org/10.1016/j.enpol.2013.05.037.

[20] Y.G. Yohanis, J.D. Mondol, A. Wright, B. Norton, Real-life energy use in the UK: How occupancy and dwelling characteristics affect domestic electricity use, Energy Build. 40 (6) (2008) 1053-1059, https://doi.org/10.1016/j. enbuild.2007.09.001.

[21] G. Huebner, D. Shipworth, I. Hamilton, Z. Chalabi, T. Oreszczyn, Understanding electricity consumption: A comparative contribution of building factors, sociodemographics, appliances, behaviours and attitudes, Appl. Energy 177 (2016) 692-702, https://doi.org/10.1016/j.apenergy.2016.04.075.

[22] R.A. Cox, M. Drews, C. Rode, S.B. Nielsen, Simple future weather files for estimating heating and cooling demand, Build. Environ. 83 (2015) 104-114, https://doi.org/10.1016/j.buildenv.2014.04.006.

[23] F. McLoughlin, A. Duffy, M. Conlon, Characterising domestic electricity consumption patterns by dwelling and occupant socio-economic variables: An Irish case study, Energy Build. 48 (2012) 240-248, https://doi.org/10.1016/ j.enbuild.2012.01.037.

[24] D. Popescu, F. Ungureanu, A. Hernández-Guerrero, Simulation models for the analysis of space heat consumption of buildings, Energy 34 (10) (2009) 1447 1453, https://doi.org/10.1016/j.energy.2009.05.035.

[25] E. Vittinghoff, D.V. Glidden, S.C. Shiboski, C.E. McCulloch, Regression Methods in Biostatistics, Springer 2012, Doi: 10.1007/978-1-4614-1353-0.

[26] G. James, D. Witten, T. Hastie, R. Tibshirani, An Introduction to Statistical Learning with Applications in R. vol. 64. 2013.

[27] R. Johnston, K. Jones, D. Manley, Confounding and collinearity in regression analysis: a cautionary tale and an alternative procedure, illustrated by studies of British voting behaviour, Qual. Quant. 52 (4) (2018) 1957-1976, https://doi. org/10.1007/s11135-017-0584-6.

[28] M. Santamouris, C. Cartalis, A. Synnefa, D. Kolokotsa, On the impact of urban heat island and global warming on the power demand and electricity consumption of buildings - A review, Energy Build. 98 (2015) 119-124, https://doi.org/10.1016/j.enbuild.2014.09.052.

[29] M. Santamouris, Energy Consumption in the European Built Environment - The Role of Cooling, 2015.

[30] W. Abrahamse, L. Steg, C. Vlek, T. Rothengatter, A review of intervention studies aimed at household energy conservation, J Environ Psychol 25 (3) (2005) 273-291, https://doi.org/10.1016/j.jenvp.2005.08.002.

[31] G.M. Huebner, J. Cooper, K. Jones, Domestic energy consumption - What role do comfort, habit, and knowledge about the heating system play?, Energy Build 66 (2013) 626-636, https://doi.org/10.1016/j.enbuild.2013.07.043.

[32] S. Darby, The Effectiveness of Feedback on Energy Consumption, a Review for DEFRA of the Literature on Metering, Billing and Direct Displays, Oxford Environ Chang Inst, 2006.

[33] A. Nilsson, C.J. Bergstad, L. Thuvander, D. Andersson, K. Andersson, P. Meiling, Effects of continuous feedback on households' electricity consumption: Potentials and barriers, Appl. Energy 122 (2014) 17-23, https://doi.org/ 10.1016/j.apenergy.2014.01.060. 
[34] K. Vringer, T. Aalbers, K. Blok, Household energy requirement and value patterns, Energy Policy 35 (1) (2007) 553-566, https://doi.org/10.1016/j. enpol.2005.12.025.

[35] G. Brandon, A. Lewis, Reducing household energy consumption: A qualitative and quantitative field study, J Environ Psychol 19 (1)(1999) 75-85, https://doi. org/10.1006/jevp.1998.0105.

[36] A.M.R. Nishimwe, S. Reiter, Building heat consumption and heat demand assessment, characterization, and mapping on a regional scale: A case study of the Walloon building stock in Belgium. Renew Sustain Energy Rev 2021;135. doi:10.1016/j.rser.2020.110170.

[37] X. Cao, J. Wang, J. Chen, F. Shi, Spatialization of electricity consumption of China using saturation-corrected DMSP-OLS data, Int. J. Appl. Earth Obs. Geoinf. 28 (2014) 193-200, https://doi.org/10.1016/j.jag.2013.12.004.

[38] K. Shi, Q. Yang, G. Fang, B. Yu, Z. Chen, C. Yang, J. Wu, Evaluating spatiotemporal patterns of urban electricity consumption within different spatial boundaries: A case study of Chongqing, China. Energy 167 (2019) 641653, https://doi.org/10.1016/j.energy.2018.11.022.

[39] A. Bourgeois, M. Pellegrino, J.P. Lévy, Modeling and mapping domestic energy behavior: Insights from a consumer survey in France, Energy Res. Soc. Sci. 32 (2017) 180-192, https://doi.org/10.1016/j.erss.2017.06.021.

[40] ICEDD. Bilan Énergétique de la Wallonie 2012 Secteur Domestique et Équivalents, 2014.

[41] ICEDD. Bilan Énergétique de la Wallonie 2012 Bilan de l'Industrie et Bilan Global, 2014.

[42] Nishimwe AMR, Reiter S. Using Artificial Intelligence Models and Degree-Days Method to Estimate the Heat Consumption Evolution of a Building Stock Until 2050: A Case Study in a Temperate Climate of the Northern Part of Europe. Under Review, unpublished results, 2021.

[43] Statbel. Géographie administrative | Statbel n.d. https://statbel.fgov.be/fr/ propos-de-statbel/methodologie/classifications/geographie-administrative (accessed June 13, 2018).

[44] Van Hecke E, Halleux J-M, Decroly J-M, Mérenne-Schoumaker B. Noyaux d'habitat et Régions urbaines dans une Belgique urbanisée 2009:201.

[45] Service public de Wallonie. Géoportail de la Wallonie, 2015.

[46] Catalogue des indicateurs statistiques - WALSTAT n.d. https://walstat.iweps. be/walstat-catalogue.php?

niveau_agre $=C \&$ indicateur_id $=201000 \&$ ordre $=0$ \&periode $=01 / 01 /$

2017\&niveau_agre=A\&sel_niveau_catalogue=T (accessed May 20, 2018).

[47] O. Sidler, Analyse de la consommation énergétique des ménages en Belgique. vol (2019) 2016.
[48] J. Spinoni, J.V. Vogt, P. Barbosa, A. Dosio, N. McCormick, A. Bigano, H.-M. Füssel, Changes of heating and cooling degree-days in Europe from 1981 to 2100, Int. J. Climatol. 38 (2018) e191-e208, https://doi.org/10.1002/joc.2018.38.issueS110.1002/joc.5362.

[49] A. Gilg, S. Barr, N. Ford, Green consumption or sustainable lifestyles? Identifying the sustainable consumer, Futures 37 (6) (2005) 481-504, https://doi.org/10.1016/j.futures.2004.10.016.

[50] T. Smallbone, How can domestic households become part of the solution to England's recycling problems?, Bus Strateg. Environ, 14 (2) (2005) 110-122, https://doi.org/10.1002/bse.v14:210.1002/bse.442.

[51] A. Matzarakis, F. Thomsen, H. Mayer, Climate change and heating degree days in Freiburg im Breisgau, south-west Germany. Gefahrstoffe Reinhaltung Der Luft 2009, 69.

[52] A. Must, K.E. Peterson, G.A. Colditz, S.L. Gortmaker, A.M. Sobol, K. Peterson, et al., Television Viewing as a Cause of Increasing Obesity Among Children in the United States, 1986-1990, Arch. Pediatr. Adolesc. Med. (1996), https://doi. org/10.1038/oby.2002.55.

[53] T.N. Robinson, Reducing children's television viewing to prevent obesity: A randomized controlled trial, J. Am. Med. Assoc. 282 (1999) 1561-1567, https:/I doi.org/10.1001/jama.282.16.1561.

[54] A. Grøntved, F.B. Hu, Television viewing and risk of type 2 diabetes, cardiovascular disease, and all-cause mortality: A meta-analysis, JAMA - J Am Med Assoc 305 (2011) 2448-2455, https://doi.org/10.1001/jama. 2011.812.

[55] K. Wijndaele, S. Brage, H. Besson, K.T. Khaw, S.J. Sharp, R. Luben, et al. Television viewing and incident cardiovascular disease: Prospective associations and mediation analysis in the EPIC norfolk study. PLoS One 2011;6. doi:10.1371/journal.pone.0020058.

[56] WalStat. Catalogue des indicateurs statistiques - WALSTAT. Iweps n.d. https:// walstat.iweps.be/walstat-catalogue.php?niveau_agre $=C \&$ theme_id $=16 \&$ indicateur_id=811400\&sel_niveau_catalogue $=$ C\&ordre $=6$ (accessed February 24, 2021).

[57] D. Ramon, K. Allacker, N.P.M. van Lipzig, F. De Troyer, H. Wouters, Future Weather Data for Dynamic Building Energy Simulations: Overview of Available Data and Presentation of Newly Derived Data for Belgium, Energy, Environ. Sustain., Springer, Singapore (2019) 111-138, https://doi.org/ 10.1007/978-981-13-3284-5_6.

[58] B. Dong, K.P. Lam, A real-time model predictive control for building heating and cooling systems based on the occupancy behavior pattern detection and local weather forecasting, Build. Simul. 7 (1) (2014) 89-106, https://doi.org/ 10.1007/s12273-013-0142-7. 